\title{
Distortionary tax instruments and implementable monetary policy
}

\author{
Luigi Marattin, Massimiliano Marzo and Paolo Zagaglia*
}

This version: November 17, 2009

\begin{abstract}
We introduce distortionary taxes on consumption, labor and capital income into a New Keynesian model with Calvo pricing and nominal bonds. We study the relation between tax instruments and optimal monetary policy by computing simple rules for monetary and fiscal policy when one tax instrument at a time varies, while the other two are fixed at their steady-state level. The optimal rules maximize the second-order approximation to intertemporal utility. Three results emerge: (a) when prices are sticky, perfect inflation stabilization is optimal independently from the tax instrument adopted; (b) the optimal degree of responsiveness of monetary policy to output varies depending on which tax instrument induces fluctuations in the average tax rate; (c) when prices are flexible, fiscal rules that prescribe unexpected variations in the price level to support debt changes are always welfare-maximizing.
\end{abstract}

JEL classification: E52, E61, E63.

Keywords: nominal rigidities, distortionary taxation, monetary-policy rules.

\footnotetext{
*Marattin: Department of Economics, Università di Bologna; luigi.marattin@unibo.it. Marzo: Department of Economics, Università di Bologna; massimiliano.marzo@unibo.it. Zagaglia: Modelling Unit, Sveriges Riksbank; paolo.zagaglia@gmail.com. We are grateful to Jonas Agell, Tommaso Monacelli and Ulf Söderström for insightful discussions and suggestions, and to Fabrice Collard, Stephanie Schmitt-Grohé and Martin Uribe for detailed explanations on their related work. Robert Kollmann kindly commented on an earlier draft, thus shaping most of the improvements. Financial support from Stockholm University, MIUR, and BI Norwegian School of Management is gratefully acknowledged. The views expressed herein are those of the authors only and should not be attributed to the members of the Executive Board of Sveriges Riksbank.
} 


\section{Introduction}

The literature on the quantitative aspects of the interactions between fiscal and monetary policy has recently gained a considerable degree of attention in general equilibrium macroeconomic modelling. Contributions such Schmitt-Grohé and Uribe (2005a), Marzo (2003), Kollmann (2006) and Schmitt-Grohé and Uribe (2006) evaluate the optimality of alternative combinations of fiscal and monetary policy in DSGE models, assuming that the former takes place through changes in one or two distortionary tax rates, typically labour and/or capital, or a generic output tax. In this paper we analyze the same problem when three distortionary tax rates (on consumption, labour and capital income) are available, and monetary policy is conducted via a standard Taylor rule. Our main result, contrary to what found in Schmitt-Grohé and Uribe (2006), is that the optimal degree of monetary policy's response to output varies depending on which of the above tax rates is employed as fiscal policy instrument.

The relevance of tax burden's composition is evident from the observation of the way fiscal policy is actually implemented, and can suggest that the use of an average tax rate can be a poor indicator of the true distortions on agents' marginal decisions triggered by fiscal policy. Furthermore, its relevance for the setting of monetary policy is supported by a number of results on Ramsey optimal policy. In a simpler framework with no capital accumulation, Correia, Nicolini, and Teles (2003) provide equivalence theorems on the mix between consumption and labor-income taxes as a substitute for state-contingent debt in the delivery of Ramsey allocations. However, it is unclear how the proposed allocations should be implemented for the purpose of stabilization around distorted steady states.

The aim of this paper is to fill the gap in the literature by deriving benchmark results about the impact of alternative sources of distortionary taxation on monetary policy. We build a New Keynesian DSGE model with Calvo pricing, capital accumulation and distortionary tax rates on consumption, labor and capital income. We compute optimized simple rules for monetary and fiscal policy when one tax instrument at a time varies, while keeping the other two distortionary tax rates fixed at their steady-state levels. The optimal rules maximize a measure of intertemporal (conditional) utility, in order to account fully for the transitional effects of alternative policy arrangements. To that end, we approximate the solution to the system of optimality conditions through the second-order Taylor approximation around the distorted steady states suggested by Schmitt-Grohé and Uribe (2006).

Our results contrast the findings of Schmitt-Grohé and Uribe (2006) regarding the optimality of acyclical monetary policy. We show that the optimal degree of responsiveness of monetary policy to output can depend on the instrument for tax policy. In particular, when labor-income taxes follow a simple rule, acyclical monetary policy generates indeterminacy, i.e. it is consistent with multiple equilibria. This means that the combination between rules for monetary and fiscal policy is incapable of pinning down a unique desired macroeconomic outcome. However, the choice of the optimal policy mix satisfies the logic outlined in Leeper (1991), and minimizes the welfare effects of the dispersion in markups.

Our analysis presents two additional insights concerning the interaction between fiscal and monetary policy as a function of the degree of nominal rigidities. First, when prices are sticky, inflation stabilization is optimal independently from the tax instrument considered. Hence, op- 
timal fiscal policy is 'passive' in the sense that the fluctuations of government liabilities require no adjustment to the price level in order to sustain fiscal solvency (see Leeper, 1991). This is explained by the fact that, with Calvo pricing, movements in the inflation rate generate an inefficient (welfare-reducing) dispersion of markups between the firms that change prices and those that cannot.

The second set of results indicates that, when prices are flexible, fiscal-policy rules that prescribe unexpected variations in the price level are optimal independently from the tax instrument considered. Interestingly though, the quantitative findings indicate that an fiscal policy 'active' in the sense of Leeper (1991) need not arise from a strong reaction of taxes to changes in government liabilities. The reason is that, in Leeper (1991)'s framework, taxes are lump-sum. Distortionary taxes instead affect real allocations both directly through their impact on equilibrium choices, and indirectly through inflation expectations. Thus, although the logic of Leeper (1991) applies, the quantitative dynamics is different from the baseline setting with lump-sum taxes.

The remainder of this paper is organized as follow. Section 2 builds the model under price rigidity, describing the behaviour of consumers, firms, policy authorities and equilibrium conditions. Section 3 is concerned with the exposition of the quantitative results: after giving account of calibration and computational strategies, we discuss the model's main results and present the relevant robustness checks, including the analysis of the flexible prices case. Section 4 presents some concluding remarks.

\section{The model}

The structure of the model follows the New Keynesian tradition. It combines nominal price rigidities in the form advocated by Calvo (1983) with real distortions due to monopolistic competition in intermediate-product markets. The novel element is the introduction of three forms of distortionary taxation - on consumption, labor and capital income - in the household's budget constraint. There are exogenous shocks to both productivity and government consumption.

\subsection{The household sector}

The demand side of the model economy is populated by a representative infinitely-lived consumer. The agent enjoys utility from current consumption $c_{t}$ and disutility from hours worked $\ell_{t}$. The history of events $s^{t}=\left\{s_{0}, \ldots s_{t}\right\}$ up to date $t$ is assigned a time- 0 probability mass $\mu\left(s^{t}\right)$. The uncertainty in the choice process is summarized by the conditional-expectation operator $\mathrm{E}_{0}[\cdot]:=$ $\sum_{s^{t+1}} \mu\left(s_{t+1} \mid s^{t}\right)$. Given this structure, the household's allocation problem takes the form

$$
\begin{aligned}
& \max _{\left\{c_{t}, \ell_{t}, i_{t}, k_{t+1}, A_{b, t}\right\}_{t=0}^{\infty}} \mathrm{E}_{0}\left[\sum_{t=0}^{\infty} \beta^{t} \mathrm{u}\left(c_{t}, \ell_{t}\right)\right] \\
& \text { s. t. } \begin{array}{r}
\left(1+\tau_{t}^{c}\right) C_{t}+\eta_{t} A_{b, t}+I_{t}+\leq\left(1-\tau_{t}^{\ell}\right) \\
+W_{t} \ell_{t} \\
+\left[\left(1-\tau_{t}^{k}\right) r_{t}+\tau_{t}^{k} \delta\right] K_{t}+A_{b, t-1}+\overline{T R}+\Omega_{t} .
\end{array}
\end{aligned}
$$


where the choice variables with lower-case letters are deflated by the price level. The intertemporal discount factor of the consumer is $\beta \in(0,1)$. We should stress that our framework refers to a cashless economy, which however preserves the comparability with Schmitt-Grohé and Uribe (2006), as this specificity is explicitly considered by them.

The portfolio of financial assets includes one-period riskless nominal bonds $A_{b, t}$ with price $\eta_{t}$. The representative household also owns the claims to the profit $\omega_{\iota}$ of the monopolisticallycompetitive firm $\iota$. The gross interest rate on bonds is denoted as $R_{t}$. Let $\Omega_{\iota t}$ denote the dividend stream generated by firm $\iota$ and appropriated by household. The total dividend payment to household is

$$
\Omega_{t}:=\int_{\iota \in \varpi} \omega_{\iota} \Omega_{\iota t} d \iota .
$$

For the purpose of analytical simplicity, we assume that the allocation of ownership shares across agents is constant, and beyond the control of households.

The representative consumer controls the evolution of the real capital stock $k_{t}$ through the individual decision on investment $i_{t}$. Capital services are rented to the firms of the intermediategood sector at the rate $r_{t}$. Capital accumulation follows a linear law of motion

$$
k_{t+1}=i_{t}+(1-\delta) k_{t} .
$$

Three types of distortionary taxes enter the consumer's budget constraint. There are taxes on consumption, labor income and capital income at the average rates $\tau_{t}^{c}, \tau_{t}^{\ell}$ and $\tau_{t}^{k}$ respectively. Capital taxes are imposed on the nominal return of capital. Following Kim and Kim (2003), we introduce a depreciation allowance on capital taxation, with $r_{t}$ as the rental rate of capital. Households also enjoy a nominal flow $\overline{T R}$ of real government transfers. These transfers are fixed at the steady-state level, and are introduced to improve the calibration of the model.

\subsection{The final-good sector}

The model includes a perfectly-competitive market where a representative firm sells a final product. The firm purchases intermediate goods and re-packages them through the Dixit-Stiglitz technology

$$
y_{t} \leq\left[\int_{\iota \in \varpi} y_{\iota t}^{\frac{\theta-1}{\theta}} d \iota\right]^{\frac{\theta}{\theta-1}},
$$

where $\iota$ indexes the inputs over the measure $\varpi$ of intermediate firms. The demand for each intermediate good $y_{\iota t}$ follows from the static profit maximization problem

$$
\max _{\left\{y_{\iota t}\right\}_{\iota \in \varpi}} P_{t}\left[\int_{\iota \in \varpi} y_{\iota t}^{\frac{\theta-1}{\theta}} d \iota\right]^{\frac{\theta}{\theta-1}}-\int_{\iota \in \varpi} P_{\iota t} y_{\iota t} d \iota,
$$


and takes the form

$$
y_{\iota t}=\left[\frac{P_{\iota t}}{P_{t}}\right]^{-\theta} y_{t}
$$

At a zero-profit equilibrium, the following price index of final goods can be derived

$$
P_{t}=\left[\int_{\iota \in \varpi} P_{\iota t}^{1-\theta} d \iota\right]^{\frac{1}{1-\theta}}
$$

\subsection{The intermediate-good sector}

In the intermediate sector, firm $\iota \in \varpi$ uses capital and labor as production inputs according to a constant returns-to-scale technology

$$
y_{\iota t} \leq z_{t} k_{\iota t}^{\alpha}\left(\ell_{\iota t}\right)^{1-\alpha}
$$

where $z_{t}$ is an exogenous productivity shock common to all firms

$$
\ln \left[z_{t+1}\right]=\rho_{z} \ln \left[z_{t}\right]+\sigma_{z} \epsilon_{t+1}^{z},
$$

and $\epsilon_{t}^{z} \sim \mathrm{N}(0,1)$. Capital services are rented from centralized markets, and are perfectly mobile across firms.

Each firm chooses $k_{\iota t}$ and $\ell_{\iota t}$ taking their rental rates as given. The allocation problem for production factors is

$$
\max _{\left\{\ell_{\iota t+n}, k_{\iota t+n}\right\}_{n=0}^{\infty}} \mathrm{E}_{0} \sum_{n=0}^{\infty} \Xi_{t+n \mid t} P_{t+n}\left[\frac{P_{\iota t+n}}{P_{t+n}} y_{\iota t+n}-w_{t+n} \ell_{\iota t+n}-r_{t+n} k_{\iota t+n}\right],
$$

subject to the constraints 6 and 8 . The stochastic discount factor $\Xi_{t+n \mid t}$ collects the prices of the claims that pay each one unit of money for a given state of nature at $t+n$, normalized by the probability of the state.

Sticky prices arise from staggered price contracts in the tradition of Calvo (1983). Each firm is allowed to change the price of its intermediate good with a fixed probability $1-\phi_{p}$. A price that cannot be re-set optimally in the current period increases at the steady-state rate of inflation $\bar{\pi}$. Along with the assumption of monopolistically-competitive markets, this mechanism implies that firms are willing to satisfy unexpected fluctuations in demand even if they cannot change their prices. Because of constant-returns to scale and no fixed costs, when a re-optimization takes place the price-setting decision of firm $\iota$ in period $t$ involves choosing a contingent plan for $\tilde{P}_{\iota t}$ such that

$$
\max _{\tilde{P}_{\iota t}} \mathrm{E}_{t} \sum_{n=0}^{\infty} \Xi_{t+n \mid t} \phi_{p}^{n} P_{t+n}\left[\frac{\bar{\pi}^{n} \tilde{P}_{\iota t}}{P_{t+n}} y_{\iota t+n}-\mathrm{mc}_{t+n} y_{\iota t+n}\right] .
$$

where $m c_{t+n}$ is the stream of future marginal cost of production. 


\section{$2.4 \quad$ Fiscal and monetary policy rules}

The government faces the flow budget constraint ${ }^{1}$

$$
D_{t}+P_{t} \tau_{t}=R_{t-1} D_{t-1}+P_{t} g_{t}^{c}+P_{t} \overline{t r} .
$$

Real total taxation is denoted as $\tau_{t}$, and $g_{t}$ indicates total government spending. The government issues one-period riskless (non-state contingent) nominal bonds denoted by $D_{t}$.

The total revenues from taxation are decomposed into consumption taxes $\tau_{t}^{c}$, capital taxes $\tau_{t}^{k}$ and labor taxes $\tau_{t}^{\ell}$

$$
\tau_{t}:=\tau_{t}^{c} c_{t}+\tau_{t}^{k}\left(r_{t}-\delta\right) k_{t}+\tau_{t}^{\ell} w_{t} \ell_{t}
$$

Public spending is an exogenous process

$$
\ln \left[g_{t+1}^{c}\right]=\rho_{g} \ln \left[g_{t}^{c}\right]+\left(1-\rho_{g}\right) \ln \left[\bar{g}^{c}\right]+\sigma_{g} \epsilon_{t+1}^{g} .
$$

with $\epsilon_{t}^{g} \sim \mathrm{N}(0,1)$. There are also transfers $\overline{t r}$ to households that are fixed to their steady-state level. Government transfers are introduced for the purpose of achieving a realistic calibration of the steady-state ratio between public debt and output. The intertemporal budget constraint of the government is written as

$$
R_{t} D_{t} \leq \sum_{p=0}^{\infty} \mathrm{E}_{t+p}\left(\frac{1}{R_{t+p}}\right)^{p}\left[P_{t+p} \tau_{t+p}-P_{t+p} g_{t+p}\right] .
$$

with total public spending $g_{t}:=g_{t}^{c}+\overline{t r}$. This amounts to saying that the maximum level of outstanding debt in every period should not exceed the discounted sum of future primary surpluses.

The literature on public finance provides plenty of results of equivalence between different types of taxation in terms of welfare impact. In these cases, the allocation achieved under a given tax structure can be replicated through alternative structures where the redundant tax rates are removed. Renström (2006) shows that the tax equivalence proposition breaks down in a dynamic framework where the consumption plans of households can be changed at a frequency higher than tax rates. Correia, Nicolini, and Teles (2003) provide equivalence theorems on the mix between consumption and labor-income taxes as a substitute for state-contingent debt in the delivery of Ramsey optimal allocations. Like in the seminal contribution of Ramsey (1927), these equivalence theorems arise in simplified economies that include only a limited number of frictions. This provides the motivation for including proportional tax rates on consumption, labor and capital income in the model.

From an operational point of view, the tax rates on consumption, labor and capital income are the three instruments that the government can employ for cyclical fiscal policy. In this paper, we impose a fiscal feedback rule that makes one of the tax rates change, while holding the other two constant at their steady state values. Following Schmitt-Grohé and Uribe (2006), we define the

\footnotetext{
${ }^{1}$ Our government budget constraint differs from the one employed by Schmitt-Grohé and Uribe (2006) since we do not have money issuance here.
} 
total amount of government liabilities $l_{t}$ in equilibrium $l_{t}:=R_{t} d_{t}$. Hence, the flow government budget constraint in equilibrium can be expressed in terms of total liabilities

$$
l_{t}=\frac{R_{t} l_{t-1}}{\pi_{t}}+R_{t}\left(g_{t}-\tau_{t}\right) .
$$

The evolution of total distortionary taxes is linked to the outstanding value of government liabilities through the simple rule:

$$
\tau_{t}=\psi_{0}+\psi_{1}\left(l_{t-1}-\bar{l}\right)+\psi_{2}\left[g_{t}+\left(\frac{R_{t-1}-1}{R_{t-1}}\right)\left(\frac{l_{t-1}}{\pi_{t}}\right)\right] .
$$

where $\bar{l}$ denotes the deterministic steady state of government liabilities. Suppose that the tax rate on consumption $\tau_{t}^{c}$ is the instrument for fiscal policy. From equation (17), we get

$$
\begin{aligned}
\tau_{t}^{c}=\psi_{0} / c_{t}-\left[\bar{\tau}^{k}\left(r_{t}-\delta\right) k_{t}+\right. & \left.\bar{\tau}^{\ell} w_{t} \ell_{t}\right] / c_{t} \\
& +\psi_{1}\left(l_{t-1}-\bar{l}\right) / c_{t}+\psi_{2}\left[g_{t}+\left(\frac{R_{t-1}-1}{R_{t-1}}\right)\left(\frac{l_{t-1}}{\pi_{t}}\right)\right] / c_{t} .
\end{aligned}
$$

Similar expressions can be derived for $\tau_{t}^{k}$ and $\tau_{t}^{\ell}$.

The fiscal rule 17 allows us to distinguish between two kinds of liability stabilization. A simple fiscal feedback rule à la Leeper (1991) is obtained by setting $\psi_{2}=0$, whereas a balanced budget rule holds when $\psi_{1}=0$ and $\psi_{2}=1$. In the case of liability targeting, Leeper (1991) distinguishes between two policy regimes. With 'active' fiscal policy, the evolution of government liabilities plays an important role in the determination of the price level. A 'passive' fiscal policy, instead, is such that tax policy does not constrain the path of the inflation rate. Combining the fiscal rule for liability targeting with the flow budget constraint, a linear difference equation can be obtained: $l_{t}=\left(R_{t} / \pi_{t}\right)\left(1-\psi_{1} \pi_{t}\right) l_{t-1}+$ rest. An active fiscal policy requires: $\left|1-\psi_{1} \bar{\pi}\right|>1$. This condition implies that government liabilities grow at a rate higher than the real interest rate. In order to make the problem stationary, the initial price level should adjust accordingly.

Finally, we assume that the central bank sets policy rates according to a simple feedback rule

$$
\ln \left[\frac{R_{t}}{\bar{R}}\right]=\alpha_{\pi} \ln \left[\frac{\pi_{t}}{\bar{\pi}}\right]+\alpha_{y} \ln \left[\frac{y_{t}}{\bar{y}}\right]+\alpha_{R} \ln \left[\frac{R_{t-1}}{\bar{R}}\right] .
$$

This formulation has become standard since the work of Taylor (1993).

\subsection{Aggregation and equilibrium}

Under Calvo pricing, all the firms that are allowed to change their idiosyncratic prices choose the same new price. Hence, the average price level can be written as:

$$
\left(P_{t}\right)^{1-\theta}=\phi_{p}\left(\bar{\pi} P_{t-1}\right)^{1-\theta}+\left(1-\phi_{p}\right)\left(\tilde{P}_{t}\right)^{1-\theta},
$$


which can be re-written as

$$
1=\phi_{p}\left(\frac{\bar{\pi}}{\pi_{t}}\right)^{1-\theta}+\left(1-\phi_{p}\right)\left(\tilde{p}_{t}\right)^{1-\theta},
$$

with $\tilde{p}_{t}:=\frac{\tilde{P}_{t}}{P_{t}}$ and $\pi_{t}:=\frac{P_{t}}{P_{t-1}}$.

Proposition 1 Equilibria of this set of economies are sequences of prices $\left\{\mathbf{P}_{\mathbf{t}}\right\}_{t=0}^{\infty}:=\left\{P_{t}^{*}, \tilde{P}_{t}^{*}, R_{t}^{*}, \eta_{t}^{*}, w_{t}^{*}, r_{t}^{*}, s_{t}^{*}\right\}_{t=0}^{\infty}$, quantities $\left\{\mathbf{Q}_{\mathbf{t}}\right\}_{t=0}^{\infty}:=\left\{\left\{\mathcal{Q}_{t}^{h}\right\}_{t=0}^{\infty},\left\{\mathcal{Q}_{t}^{f}\right\}_{t=0}^{\infty},\left\{\mathcal{Q}_{t}^{g}\right\}_{t=0}^{\infty}\right\}$ with $\left\{\mathcal{Q}_{t}^{h}\right\}_{t=0}^{\infty}:=\left\{c_{t}^{*}, \ell_{t}^{*}, k_{t+1}^{*}, i_{t}^{*}, a_{b, t}^{*}\right\}_{t=0}^{\infty},\left\{\mathcal{Q}_{t}^{f}\right\}_{t=0}^{\infty}:=\left\{y_{t}^{*}, k_{t}^{*}, \ell_{t}^{*}\right\}_{t=0}^{\infty},\left\{\mathcal{Q}_{t}^{g}\right\}_{t=0}^{\infty}:=\left\{g_{t}^{c *}, \overline{t r}^{*}, \tau_{t}^{c *}\right.$, $\left.\tau_{t}^{k *}, \tau_{t}^{\ell *}, d_{t}^{*}\right\}_{t=0}^{\infty}$, and stochastic shocks $\left\{\mathcal{E}_{t}\right\}_{t=0}^{\infty}:=\left\{\epsilon_{t}^{z}, \epsilon_{t}^{g}\right\}_{t=0}^{\infty}$ that are bound in a neighborhood of the deterministic steady state, and such that:

(i) given prices $\left\{\mathbf{P}_{\mathbf{t}}\right\}_{t=0}^{\infty}$ and shocks $\left\{\mathcal{E}_{t}\right\}_{t=0}^{\infty},\left\{\mathcal{Q}_{t}^{h}\right\}_{t=0}^{\infty}$ is a solution to the representative household's problem;

(ii) given prices $\left\{\mathbf{P}_{\mathbf{t}}\right\}_{t=0}^{\infty}$ and shocks $\left\{\mathcal{E}_{t}\right\}_{t=0}^{\infty},\left\{\mathcal{Q}_{t}^{f}\right\}_{t=0}^{\infty}$ is a solution to the representative problem of the firm;

(iii) given quantities $\left\{\mathbf{Q}_{\mathbf{t}}\right\}_{t=0}^{\infty}$ and shocks $\left\{\mathcal{E}_{t}\right\}_{t=0}^{\infty},\left\{\mathbf{P}_{\mathbf{t}}\right\}_{t=0}^{\infty}$ clears the markets for both goods and factors of production

$$
\begin{aligned}
& y_{t}^{*}=\left[c_{t}^{*}+i_{t}^{*}+g_{t}^{*}+\overline{t r}^{*}\right] s_{t}^{*}, \\
& s_{t}^{*}=\left(1-\phi_{p}\right)\left[\tilde{p}_{t}^{*}\right]^{-\theta}+\phi_{p}\left[\frac{\pi_{t}^{*}}{\bar{\pi}}\right]^{\theta} s_{t-1}^{*},
\end{aligned}
$$

and the markets for bonds

$$
\begin{aligned}
& R_{t}^{*}=\frac{1}{\eta_{t}^{*}}, \\
& a_{b, t}^{*}=d_{t}^{*} .
\end{aligned}
$$

(iv) given quantities $\left\{\mathbf{Q}_{\mathbf{t}}\right\}_{t=0}^{\infty}$, prices $\left\{\mathbf{P}_{\mathbf{t}}\right\}_{t=0}^{\infty}$ and shocks $\left\{\mathcal{E}_{t}\right\}_{t=0}^{\infty},\left\{\mathcal{Q}_{t}^{g}\right\}_{t=0}^{\infty}$ satisfies both the government flow and the intertemporal budget constraint;

(v) fiscal and monetary polices are set according to the simple rules outlined earlier.

\section{Quantitative results}

In this section we discuss the results of the model with price rigidity. After dealing with calibration and computational issues, we discuss the optimal cyclical response of monetary policy depending on the tax instrument employed, present the relevant set of experiments and compare our results to the contribution of Schmitt-Grohé and Uribe (2006). In the last subsection, concerned with the analysis of the flexible prices model, we show that standard results about the desiderability of monetary/fiscal policy configuration vis-a-vis the degree of nominal rigidities hold even in our more sophisticated (and distorted) framework. 


\subsection{Calibration}

we calibrate the model on quarterly data for an average G-7 economy. The parameter values are reported in Table 1. The long-run inflation rate is set to $4 \%$ a year. The intertemporal discount factor $\beta$ equals 0.9949. Households devote a steady-state share of time to market activity equal to 0.4 .

we choose an investment-output ratio of 0.24 at the steady state. The quarterly depreciation rate is consistent with an annual rate of $10 \%$. The resulting capital-output ratio (9.95) is close to what data for the U.S. suggest (see Christiano, Eichenbaum, and Evans, 2005). The pricemarginal cost markup factor is set at $\theta /(\theta-1)=1.25$, as suggested by Bayoumi, Laxton, and Pesenti (2004). Following Pappa (2004), we choose $\phi_{p}=2 / 3$, which implies an average contract duration of $1 /(1-2 / 3)=3$ quarters. The capital elasticity of output $\alpha$ is 0.4 (see Kim and Kim, 2003).

The steady-states tax rates on consumption, labor and capital income are set at, respectively, 0.12, 0.3168 and 0.36; these values, interpreted as long-run tax rates on those macroeconomic aggregates, match the G-7 averages from Kim and Kim (2003).The steady-state ratio between public debt and output is calibrated at $70 \%$, with government consumption representing a share of $15 \%$ of output. The resulting ratio between public transfers and output is approximately 0.10. In the model with lump-sum taxes, we adjust the ratio between public transfers and output to achieve a public-debt share of output of $70 \%$.

\subsection{Computational aspects}

\subsubsection{Welfare evaluation}

The coefficients of the policy rules for both monetary and fiscal policy are chosen to maximize a utility-based welfare function. In this paper, we consider a measure of conditional household welfare

$$
\mathcal{W}_{0}:=\mathrm{E}\left[\sum_{t=0}^{\infty} \beta^{t}\left(\log \left(c_{t}\right)-\gamma \ell_{t}\right) \mid \tilde{s} \sim(\underline{s}, \underline{\Omega})\right]
$$

that takes into account the transitional costs of moving from the initial state $\tilde{s}$ to the stochastic steady state of the model, with $\underline{s}$ and $\underline{\Omega}$ as the mean and the covariance matrix of the distribution of the initial state. In order to obtain accurate welfare results, we solve the model through the second-order Taylor expansion method of Schmitt-Grohè and Uribe (2004). ${ }^{2}$ The approximate solution is then used to compute the second-order expansion of the utility function so to obtain an accurate welfare criterion".

We compare the outcomes of different policies by computing the permanent change in consumption, relative to the model's steady state, that yields the expected utility level of the distorted economy. Given steady states of consumption $\bar{c}^{\iota}$ and hours worked $\bar{\ell}$ of model $\iota$, this translates

\footnotetext{
${ }^{2}$ We use the code kindly shared by Martin Uribe on his webpages.
} 
into the number $\Phi_{c}^{\iota}$ such that

$$
\sum_{t=0}^{\infty} \beta^{t} \mathrm{u}\left(\left[1-\Delta_{c}^{\iota}\right] \bar{c}^{\iota}, \bar{\ell}\right)=\mathcal{W}_{0}^{\iota}
$$

Four elements determine the size of the welfare metric. On the right-hand side of the equality, there are the deterministic steady state, its stochastic counterpart, and the transition from the deterministic to the stochastic long-run equilibrium of $\iota$. On the left-hand side, instead, there are the deterministic steady states of the benchmark model with respect to which the current distorted economy is compared. In expression 25, we follow the standard practice of using the model's own steady states as the benchmark.

Following Kollmann (2006), we decompose the conditional welfare cost $\Delta_{c}^{\iota}$ into two components denoted as $\Delta_{E}^{\iota}$ and $\Delta_{V}^{\iota}$. Denoting by hats the log-deviations from the deterministic steady state, the following approximation holds:

$$
\mathrm{u}\left(\left[1-\Delta_{c}^{\iota}\right] \bar{c}, \bar{\ell}\right) \approx \mathrm{u}(\bar{c}, \bar{\ell})+(1-\beta) \sum_{t=0}^{\infty} \beta^{t}\left(\mathrm{E}\left[\hat{c}_{t}-\bar{\ell} \hat{\ell}_{t} \mid s_{0}\right]-\frac{1}{2} \operatorname{VAR}\left[\hat{c}_{t} \mid s_{0}\right]\right)
$$

we compute the change in mean consumption $\Delta_{E}^{\iota}$ that the household faces while giving up the total fraction of certainty-equivalent consumption $\Delta_{c}^{\iota}$

$$
\mathrm{u}\left(\left[1-\Delta_{E}^{\iota}\right] \bar{c}, \bar{\ell}\right)=\mathrm{u}(\bar{c}, \bar{\ell})+(1-\beta) \sum_{t=0}^{\infty} \beta^{t}\left(\mathrm{E}\left[\hat{c}_{t} \mid s_{0}\right]-\bar{\ell} \mathrm{E}\left[\hat{\ell}_{t} \mid s_{0}\right]\right) .
$$

Since the solution method is non-certainty equivalent, we can also calculate the change in conditional variance of consumption that is consistent with the total welfare cost of policies

$$
\mathrm{u}\left(\left[1-\Delta_{V}^{\iota}\right] \bar{c}, \bar{\ell}\right)=\mathrm{u}(\bar{c}, \bar{\ell})-(1-\beta) \frac{1}{2} \sum_{t=0}^{\infty} \beta^{t} \operatorname{VAR}\left[\hat{c}_{t} \mid s_{0}\right]
$$

where hats denote log-deviations from the deterministic steady states. It can be shown that the three measures of welfare are linked in the following way:

$$
\left(1-\Delta_{c}^{\iota}\right)=\left(1-\Delta_{E}^{\iota}\right)\left(1-\Delta_{V}^{\iota}\right)
$$

Since there are no closed-form solutions for the infinite summations in the expressions for $\Delta_{V}^{\iota}$ and $\Delta_{E}^{\iota}$, we simulate the conditional moments for 10000 periods and compute the discounted sum. The (finite-horizon) conditional moments are computed through the analytical formulas presented in Appendix E.

\subsubsection{Local validity of approximate solutions}

Second-order perturbations are defined only within small neighborhoods around the approximation points, unless the function to be evaluated is globally analytic (see Anderson, Levin, and Swanson, 2004). Since the conditions for an analytic form of the policy function are hardly establishable, the problem of validity of the Taylor expansion remains. We approach this issue at 
different levels. First, we calibrate the processes for exogenous shocks in such a way that their fluctuations are constrained within small intervals, like Schmitt-Grohé and Uribe (2006). However, given the large degree of inertia in public debt fluctuations induced by the fiscal rules, this might not be enough to guarantee the local validity of the approximation.

The second step consists in imposing a constraint on the simulated values that restricts the unconditional mean of public debt to be arbitrarily close to its the deterministic steady state. This means that the stochastic steady state of public debt fluctuates within a small range around the deterministic steady state. In this, we follow Kollmann (2006). For a variable $x$, the constraint takes the form

$$
|\mathrm{E}[\hat{b}]|<\kappa_{1}
$$

This constraint is made operational in the following way. We solve the model and simulate it to obtain the conditional moments as discussed in the previous subsection. During the simulation, we discard the parameter combinations of the fiscal and monetary policy rules that produce unconditional means of public debt which do not comply with the restriction 30 .

The reason for introducing this type of constraint relates to the large persistence induced by the fiscal-policy rule, which could make the stochastic steady states drift far apart from the deterministic steady states. In that case, the Taylor approximation to the system of first-order conditions would not be locally valid any longer. The parameter $\kappa_{1}$ is calibrated equal to $0.01 .^{3}$

\subsection{Main results with price rigidity}

In this subsection, we present the results with simple rules for a policy mix in the model with price rigidity that: (a) generate unique rational-expectations equilibria; (b) achieve the highest level of conditional welfare in the admissible region of parameters for the policy rules; (c) comply with the constraint 30 . We compute the welfare-maximizing values of the parameters for the fiscal and monetary policy rules over a grid. The parameter $\psi_{1}$ is allowed to vary within $[0,4]$. The inflation coefficient $\alpha_{\pi}$ takes values in [0,2]. The parameters $\alpha_{y}$ and $\alpha_{R}$ are bound over $[0,1] .{ }^{4}$

\subsubsection{Cyclical monetary policy and tax instruments}

Table 2 is the key table summarizing our results. It reports the coefficients of the policy rules with the associated welfare level and costs under five different specifications. Our main discussion stems from panel [a], which reports the results of the fully-optimized (unconstrained) rules maximizing the measure of conditional welfare $\mathcal{W}_{0}$. The remaining configurations (panels [b]-[e]) analyze ad-hoc policy rules and are meant mainly to verify the robustness of the crucial results.

Firstly, panel [a] shows that optimal monetary policy follows the Taylor principle, namely the prescription that the coefficients on the inflation objective should be larger than one. When lump-sum taxes are the fiscal-policy instrument, all the values of $\psi_{1}$ that generate unique rationalexpectations equilibria share the same welfare level. This is due to the fact that the real allocation

\footnotetext{
${ }^{3}$ Numerical experiments show that the results are substantially unaffected for $\kappa_{1} \leq 0.05$ and $\kappa_{1} \leq 0.1$.

${ }^{4}$ We should emphasize that the results do not change if we allow the coefficient on the output gap to exceed unity.
} 
is unaffected by fiscal policy when taxes are lump-sum and follow a passive rule. However, the key result from panel [a] of Table 2 is that the optimal degree of cyclicality in monetary policy depends on the policy mix. Except for the case of time-varying taxes on labor, optimal monetary policy does not respond to output. Instead, with a policy rule for labor-income taxes, the optimized coefficient on the gap between current and long-run output ${ }^{5}$ takes the largest value within the admissible range.

Some insight on the role of cyclical monetary policy can be gained by looking at the pattern of macroeconomic adjustment generated by the optimizing policy mix. Figures 1(a)-1(d) report the impulse responses from monetary-policy rules that maximize conditional welfare with and without response to the output gap. Three aspects are worth noting. First, for a given degree of responsiveness of monetary policy to output, the initial sign of the responses of the variables is the same under all the tax instruments, with the exception of the rule for labor-income taxes. The difference lies only in the quantitative magnitude of the fluctuations. Second, like for lumpsum taxes, with a policy rule for taxes on either consumption or capital income, the nominal rate of interest rises modestly when monetary policy is acyclical, and falls when the central bank pursues a cyclical stance after a positive productivity shock. Finally, in the case of labor-income taxes (see figure 1(d)), acyclical monetary policy generates multiple equilibria, and the corresponding impulse responses cannot be computed without further assumptions on the mechanism of equilibrium selection.

The fall of policy rates when the central bank leans against the wind' appears counterintuitive. In particular, one would expect the presence of a cyclical component to strengthen the response of monetary policy to a positive supply shock. This indicates that there should be an inverse relation between inflation variability and the output coefficient of the Taylor rule. Figure 2 plots the variance of $\pi_{t}$ as a function of $\alpha_{y}$, where all the policy parameters are chosen to maximize conditional welfare. Except for the case of time-varying taxes on labor income, figure 2 indicates that inflation variability is a monotonic increasing function of the responsiveness to output. As a result, the fall of inflation after a productivity shock is larger the higher the coefficient on the output gap.

Schmitt-Grohé and Uribe (2006) suggest that inflation changes following positive supply shocks have important welfare implications. Given the structure of the Calvo setting, the fraction of firms that are allowed to change prices makes the relative price $\tilde{P}_{t} / P_{t}$ drop. Since the markups of these firms will keep close to the steady state, their real marginal costs fall. As a result, the markups of the firms that cannot change prices are bound to increase, thus raising the economy-wide markup. The inefficient dispersion of markups explains why cyclical monetary policy is welfare-reducing.

With time-varying taxes on labor income, the optimal response to a positive productivity shock induces a fall in the nominal rate of interest. Hence, the optimizing policy mix with timevarying taxes on labor does not eliminate the inefficiency from markup dispersion. In order to provide intuition, figure 3 reports the impulse responses from a positive productivity shock for the policy rules that maximize conditional welfare as a function of $\alpha_{y}$. While varying the coefficient

\footnotetext{
${ }^{5}$ Coherently with the model-solution method, we use the expression 'output gap' to denote the deviation of current output from the distorted deterministic steady state. This differs from the notion usually employed in the literature on monetary-policy rules, which refers to the output deviation from frictionless potential output.
} 
on the output gap, the other policy parameters are set so that conditional welfare is maximized. There are two forces at work. On one hand, the globally-optimizing coefficient on the output gap objective induces the smallest initial fall in the interest rate. This is consistent with the smallest initial fall in prices. On the other, the magnitude of the initial response of the real return of capital drops as a function of $\alpha_{y}$ because capital accumulation becomes more sluggish. At the same time, the fraction of output absorbed by household bond holdings rises.

Another key ingredient in the macroeconomic adjustment with time-varying taxes for labor income is the fact that hours worked fall after a positive productivity shock (see figure $1(\mathrm{~d})$ ). With Calvo pricing, the fraction of firms that cannot change prices reduces the amount of labor services employed as a response to transitory technological improvements. This happens independently from the operative instrument for fiscal policy. However, when labor taxes are the fiscal-policy instrument, the overall quantitative impact of the monopolistic distortion on the aggregate demand for labor is negative.

The decline in hours worked is due also to the sluggish adjustment in consumption and capital. The response of capital to the positive productivity shock is small because of the inertial reaction of investment, which causes the rental rate of capital to fall on impact. Since both consumption and investment respond by little, the time share devoted to leisure must increase in order to contain the rise in output.

These considerations shed light on patterns different from those discussed in the literature. In particular, Schmitt-Grohé and Uribe (2006) argue that responding to the output gap is suboptimal for the class of Taylor rules considered here. Using the standard New Keynesian model, they find that the welfare costs of policy mistakes are increasing in the responsiveness of monetary policy to output. The results discussed here indicate that this consideration need not hold across tax instruments. Figure 4 plots the percentage changes of welfare costs from the minimized costs as a function of $\alpha_{y}$, holding the other parameters of the policy rules at the optimal levels. Two lessons emerge. The first one is that, with the exception of time-varying taxes on consumption, policies that are too responsive to output with respect to the optimal setup do not cause large welfare losses. The second is that sound monetary policy need not stick to responding to inflation alone. When labor-income taxes follow a simple policy rule, underestimating the optimal response to output raises the welfare costs by the same magnitude of the policy mistakes under time-varying taxes for capital income.

\subsubsection{The value of tax instruments}

The negative response of labor supply to a positive productivity shock is at the root of an additional aspect, that is the fact that the minimized welfare costs fall as monetary policy becomes more responsive to output. Figure 5 plots the percentage change of the welfare costs minimized at each admissible value of $\alpha_{y}$ with respect to the welfare costs of optimal policy mix. All the policy parameters are chosen so that conditional welfare is maximized for each value of the output-gap coefficient of the Taylor rule. The introduction of time-varying taxes for labor income makes the welfare-cost curve downward-sloping in the responsiveness of monetary policy to output. As noticed earlier, this is explained by the fact that the drop in hours worked is an increasing function of the welfare-maximizing values of $\alpha_{y}$ (see figure 3). The larger the fall of hours worked, the 
lower the initial drop of the inflation rate, and the lower the dynamic distortions due to markup changes.

Two points are worth noting from figure 2. When taxes on labor income are the instrument for fiscal policy, the variance of inflation is negatively related to $\alpha_{y}$. This is coherent with the pattern documented above. The important aspect is that the optimal policy mix minimizes the variability of inflation. With the exception of time-varying taxes for labor income, the policy rules achieve perfect inflation stabilization around the distorted steady state. Kollmann (2006) obtains this result by choosing a welfare-maximizing equilibrium with a high inflation coefficient in the Taylor rule. The results presented here, instead, indicate that the size of the feedback parameter on inflation need not matter as long as the Taylor principle holds.

An additional measure of the value of alternative tax instruments is provided in figure 6 . This figure plots the percentage change in welfare costs from the minimized cost as a function of the tax responsiveness to government liabilities, holding the other parameters at the welfare-maximizing values. Figure 6 shows that a lack of response to total liabilities exacerbates the welfare loss in the case of time-varying taxes for capital income. Fiscal-policy mistakes have no significant impact with time-varying taxes on consumption and labor income.

\subsubsection{The role of interest-rate inertia}

The optimized policy mix with lump-sum taxes incorporates a large degree of interest-rate inertia. However, this feature is not constant across tax instruments. In the model with time-varying taxes on labor income, monetary policy exhibits no smoothing. Panel [b] of Table 2 restricts the optimized Taylor rules to having no interest-rate inertia. With the exception of the policy rule for lump-sum taxes, there are no large falls in welfare from not responding to the past policy stance. Figure 7 reports the percentage increase in welfare costs due to policy mistakes in the choice of $\alpha_{R}$. The results indicate that these policy mistakes have only a limited impact on welfare. Hence, although the optimal degree of policy inertia is different across fiscal-policy instruments, deviations from the optimal values can be tolerated. This confirms that autocorrelation in the policy rates plays a minor role for the implementable policy mix.

\subsubsection{Ad-hoc policy rules}

A natural benchmark for comparing the performance of the fully-optimized policy mix is the parametrization proposed by Taylor (1993) for monetary policy. To that end, we search for the constrained rules with $\alpha_{\pi}=1.5, \alpha_{y}=0.5$ and $\alpha_{R}=0$ that maximize conditional welfare over $\psi_{1}$. Panel [c] of table 2 shows that the model with lump-sum taxes displays the largest fall in the level of conditional welfare. Among the distortionary tax instruments, the rule with time-varying taxes on capital income generates a sizeable increase in welfare costs.

In many formulations of DSGE models, a common assumption regarding the way tax revenue is rebated to households in a lump-sum fashion so to continuosly balance the budget makes the government flow budget constraint a trivial equilibrium condition, which thus drops out of the model. Panel [d] of Table 2 reports the optimized rules for monetary policy with balanced budget rules. Since there are only few grid points with determinate equilibria, we omit the results for capital-income taxes. The pattern of cyclicality across fiscal-policy instruments is the same as 
with the fully-optimized policy mix. Balanced budget rules achieve the same welfare levels of simple feedback rules. The only difference concerns the case of labor-income taxes, for which the transition towards the stochastic steady states is more costly than for fully-optimal policy rules.

\subsubsection{Inflation targeting}

The optimal policy rules of panel [a] achieve perfect inflation stabilization around the distorted steady state. Hence, it is interesting to consider the optimal policy mix where monetary policy contemplates constant inflation. Panel [e] of Table 2 reports the welfare-maximizing coefficients for a simple rule for monetary policy with $\hat{\pi}_{t}=0$. The optimized parameters involve a responsiveness of taxes to government liabilities that is not substantially different from those of panel [a]. However, the conditional costs in variance are very small. With time-varying taxes on capital income, the achieved welfare level is slightly higher than that under the rule from panel [a].

\subsection{An economy with flexible prices}

In a model with price stickiness and nominal debt, the distortions generated by markup changes are the key for interpreting the welfare implications of the mix between fiscal and monetary policy. In this section, we consider a setting with flexible prices where inflation does not lead to inefficient price dispersion. As a result, unanticipated inflation changes that realign the real value of public debt to that prescribed by the intertemporal solvency condition are no longer welfare reducing.

Kollmann (2006) shows that the adoption of an active stance for fiscal policy induces large inflation volatility. In the context of simple linear rules for monetary policy, this can be a source of excessive variability in the nominal interest rate. The local validity of the approximate solution might not hold any longer. Hence, along with the exogenous bound 30, we impose a condition that rules out excessive aggressiveness in the conduct of monetary policy:

$$
\mathrm{E}\left[R_{t}\right]>2 \sigma_{\hat{R}_{t}} .
$$

Large deviations of the nominal interest rate from the steady state are also likely to prescribe violations of the zero bound at some point in time (see Schmitt-Grohé and Uribe, 2005b). Enforcing the constraint 31 is consistent with imposing a zero lower bound on policy rates.

Table 3 reports the policy coefficients that maximize conditional welfare. Three main results emerge. First, except for the case of time-varying taxes on consumption, the optimal policy mix entails active fiscal policy $\left(\psi_{1} \geq 2\right)$ and passive monetary policy $\left(\alpha_{\pi}<1\right)$. Second, like in the model with price rigidity, optimal monetary policy can respond to output depending on the tax instrument adopted. Third, optimal monetary policy is characterized by no interest-rate inertia $\left(\alpha_{R}=0\right)$.

The optimality of active fiscal policy follows from the lack of welfare costs due to price changes. The analysis of Leeper (1991) suggests that, in this case, the response coefficient of taxes to government liabilities should be large. Thus, it is interesting to investigate the reason for which this prescription does not hold in the case of a policy rule for consumption taxes.

Figure 8 plots the impulse responses to a positive productivity shock when the optimized tax rule is restricted to the active and passive regions, as suggested in Leeper (1991). When fiscal 
policy is constrained to the standard region of activeness - i.e. $\psi_{1} \in[2,4]-$, the optimizing rule for monetary policy is $\hat{R}_{t}=1.1 \hat{\pi}_{t}+0.3 \hat{y}_{t}$, and is very similar to one from panel [a] of Table 3. Figure 8 shows that the drop of inflation on impact for $\psi_{1} \in[0,1.9]$ is larger than the drop for $\psi_{1} \in[2,4]$. This is due to the fact that, in order to generate a response of consumption of equal magnitude irrespective of $\psi_{1}$, the required increase of the outstanding level of debt is larger under $\psi_{1} \in[0,1.9]$ than under $\psi_{1} \in[2,4]$. Figure 10(b) plots the percentage change with respect to the minimized welfare cost as a function of $\psi_{1}$, while holding the other parameters at the welfare-maximizing level. With time-varying taxes on consumption, the closer the tax rule gets to the region with $\psi_{1} \in[2,4]$, the larger the welfare costs become.

Summing up, with flexible prices and time-varying consumption taxes, a policy mix with a low feedback coefficient on total liabilities supports a Pareto-improving allocation. In particular, the distinction between 'active' and 'passive' policy based on the quantitative reaction of taxes to government liabilities can lead to misleading conclusions when taxes are distortionary. The reason is that changes to distortionary taxes affect both the inflation rate in the initial period through their expected impact on the government flow budget constraint, and the real allocations at each point in time.

The subsequent point of interest concerns the optimal responsiveness of monetary policy to output with flexible prices. Figure 10 compares the impulse responses to a productivity shock for welfare-optimizing policy rules with $\alpha_{y}=0$ and $\alpha_{y}>0$. We can see that, independently from the instrument for fiscal policy, the optimizing degree of responsiveness to output generates the largest reaction of inflation on impact. This confirms the results discussed earlier. Table 4 reports the variability of some selected macroeconomic variables under alternative policy rules. The third and fourth columns confirm that the optimal policy mix maximizes the variance of inflation. Table 4 shows also that, when inflation variability is large, also the variance of the nominal interest rate is sizeable. Despite this, all the optimal rules underlying Table 4 comply with the bound 31 that rules out excessive aggressiveness in monetary policy, and that preserves the stationarity of the solution. Figure 11 suggests that, except in the case of time-varying lumpsum taxes, deviations from the optimal coefficient on the output gap lead to a substantial drop in the optimized welfare level.

A final note concerns the optimal degree of policy inertia. Mistakes in the choice of this parameter lead to non-existence of valid equilibria with time-varying taxes on capital income and lump-sum. Figure 12 shows that, with a policy rule for consumption taxes, the increase in welfare costs can be substantial as it goes up to $15 \%$ as $\alpha_{y}$ approaches 1 .

\section{Conclusion}

This paper studies the role of tax composition for the optimal design of simple rules for monetary and fiscal policy. We formulate a New Keynesian model with Calvo pricing and three types of distortionary taxes - taxes on consumption, capital and labor income. We assume that one of the tax rates varies at a time as a function of the deviation of government liabilities from the deterministic steady state. The second-order approximation method of Schmitt-Grohé and Uribe (2004) is used to obtain a nonlinear solution, and to compute welfare-maximizing coefficients for 
the policy rules.

Three main results emerge. In a model with price stickiness, inflation stabilization is optimal independently from the tax instrument considered, and optimal fiscal policy is passive in the sense of Leeper (1991). Differently from Schmitt-Grohé and Uribe (2006), we find that the optimal degree of responsiveness of monetary policy to output can depend on the instrument for tax policy. In particular, when labor-income taxes follow a simple policy rule, underestimating the optimal response to output can lead to a substantial welfare loss. This is due to the fact that acyclical monetary policy is unable to pin down unique macroeconomic equilibria, and the policy mix produces different outcomes that are equally achievable by the policy planner. Finally, with flexible prices, 'active' rules for fiscal policy that prescribe unexpected variations in the price level are optimal independently from the tax instrument. This confirms the results obtained by Kollmann (2006). 


\section{A First-order conditions}

The first-order conditions from the firm's allocation problem are

$$
\begin{aligned}
& w_{t}=\mathrm{mc}_{\iota t}(1-\alpha) z_{t} k_{\iota t}^{\alpha}\left(\ell_{\iota t}\right)^{-\alpha}, \\
& r_{t}=\mathrm{mc}_{\iota t} \alpha z_{t}\left[\frac{\ell_{\iota t}}{k_{\iota t}}\right]^{1-\alpha} .
\end{aligned}
$$

with real marginal costs per unit of output $\mathrm{mc}_{\iota t}$.

Optimal price decisions for firms that can adjust prices at $t$ follow from the optimality condition

$$
\mathrm{E}_{t} \sum_{n=0}^{\infty} \Xi_{t+n \mid t} \phi_{p}^{n}\left[\frac{1-\theta}{\theta} \frac{\bar{\pi}^{n} \tilde{P}_{\iota t}}{P_{t+n}}+\mathrm{mc}_{t+n}\right]\left(\frac{\bar{\pi}^{n} \tilde{P}_{\iota t}}{P_{t+n}}\right)^{-\theta-1} y_{t+n}=0 .
$$

After deflating the household's budget constraint by the price level, we obtain the following from the consumer's optimization problem

$$
\begin{aligned}
& \mathrm{u}_{c}=\left(1+\tau_{t}^{c}\right) \varsigma_{t}, \\
& \mathrm{u}_{\ell}=-\left(1-\tau_{t}^{\ell}\right) w_{t} \varsigma_{t}, \\
& \eta_{t}=\beta \mathbb{E}_{t} \frac{\varsigma_{t+1}}{\varsigma_{t} \pi_{t+1}}, \\
& \mathrm{E}_{t} \frac{\varsigma_{t+1}}{\varsigma_{t}}\left[\left(1-\tau_{t+1}^{k}\right) r_{t+1}+\tau_{t+1}^{k} \delta\right]+(1-\delta) \mathrm{E}_{t} \frac{\varsigma_{t+1}}{\varsigma_{t}}=\frac{1}{\beta},
\end{aligned}
$$

where $\varsigma_{t}$ is the Lagrange multiplier on the budget constraint.

\section{B Equilibrium price dispersion}

Definition 1 The price-dispersion term $s_{t}$ can be arranged as:

$$
\begin{aligned}
s_{t} & :=\int_{0}^{1}\left[\frac{P_{\iota t}}{P_{t}}\right]^{-\theta} d \iota \\
& =\left(1-\phi_{p}\right)\left[\frac{\tilde{P}_{t}}{P_{t}}\right]^{-\theta}+\left(1-\phi_{p}\right) \phi_{p}\left[\frac{\bar{\pi} \tilde{P}_{t-1}}{P_{t}}\right]^{-\theta}+\left(1-\phi_{p}\right) \phi_{p}^{2}\left[\frac{\bar{\pi}^{2} \tilde{P}_{t-2}}{P_{t}}\right]^{-\theta}+\ldots \\
& =\left(1-\phi_{p}\right) \sum_{j=0}^{+\infty} \phi_{p}^{j}\left[\frac{\bar{\pi}^{j} \tilde{P}_{t-j}}{P_{t}}\right]^{-\theta} \\
& =\left(1-\phi_{p}\right) \tilde{p}_{t}^{-\theta}+\phi_{p}\left[\frac{\pi_{t}}{\bar{\pi}}\right]^{\theta} s_{t-1} .
\end{aligned}
$$

Proof. It follows from the assumptions that only the histories of no price re-optimization matter for price-setting decisions, and that price re-negotiations set the same new prices.

Proposition 2 Equation (34) can be re-written in a recursive fashion:

$$
x_{t}^{1}=\frac{\theta-1}{\theta} x_{t}^{2},
$$


with the following terms:

$$
\begin{aligned}
x_{t}^{1} & :=\mathrm{E}_{t} \sum_{n=0}^{\infty} \Xi_{t+n \mid t} \phi_{p}^{n} \mathrm{mc}_{t+n}\left(\frac{\bar{\pi}^{n} \tilde{P}_{t}}{P_{t+n}}\right)^{-\theta-1} y_{t+n} \\
& =\mathrm{mc}_{t}\left[\tilde{p}_{t}\right]^{-\theta-1} y_{t}+\phi_{p} \mathrm{E}_{t} \Xi_{t+1 \mid t}\left[\frac{\bar{\pi} \tilde{p}_{t}}{\pi_{t+1} \tilde{p}_{t+1}}\right]^{-\theta-1} x_{t+1}^{1}, \\
x_{t}^{2} & :=\mathrm{E}_{t} \sum_{n=0}^{\infty} \Xi_{t+n \mid t} \phi_{p}^{n}\left(\frac{\bar{\pi}^{n} \tilde{P}_{t}}{P_{t+n}}\right)^{-\theta} y_{t+n} \\
& =[\tilde{p}]_{t}^{-\theta} y_{t}+\phi_{p} \mathrm{E}_{t} \Xi_{t+1 \mid t}\left[\frac{\bar{\pi} \tilde{p}_{t}}{\pi_{t+1} \tilde{p}_{t+1}}\right]^{-\theta} x_{t+1}^{2}, \\
\tilde{p}_{t} & :=\frac{\tilde{P}_{t}}{P_{t}} .
\end{aligned}
$$

\section{Model equations}

The equations coded into the solution algorithm are the following:

$$
\begin{aligned}
& 1 / c_{t}=\varsigma_{t}\left(1+\tau_{t}^{c}\right) \\
& \gamma=\left(1-\tau_{t}^{\ell}\right) w_{t} \varsigma_{t} \\
& \mathrm{E}_{t} \frac{\varsigma_{t+1}}{\varsigma_{t}} \frac{R_{t}}{\pi_{t+1}}=\frac{1}{\beta} \\
& \mathrm{E}_{t} \frac{\varsigma_{t+1}}{\varsigma_{t}}\left[\left(1-\tau_{t+1}^{k}\right) r_{t+1}+\tau_{t+1}^{k} \delta\right]+(1-\delta) \mathrm{E}_{t} \frac{\varsigma_{t+1}}{\varsigma_{t}}=\frac{1}{\beta} \\
& x_{t}^{1}=\mathrm{mc}_{t}\left[\tilde{p}_{t}\right]^{-\theta-1} y_{t}+\phi_{p} \mathrm{E}_{t} \beta \frac{\varsigma_{t+1}}{\varsigma_{t}}\left[\frac{\bar{\pi} \tilde{p}_{t}}{\pi_{t+1} \tilde{p}_{t+1}}\right]^{-\theta-1} x_{t+1}^{1} \\
& x_{t}^{1}=\frac{\theta-1}{\theta} x_{t}^{2} \\
& 1=\phi_{p}\left(\frac{\bar{\pi}}{\pi_{t}}\right)^{1-\theta}+\left(1-\phi_{p}\right)\left(\tilde{p}_{t}\right)^{1-\theta} \\
& (1-\alpha) \mathrm{mc}_{t} \frac{y_{t}}{\ell_{t}}=w_{t} \\
& \alpha \frac{y_{t}}{k_{t}} \mathrm{mc}_{t}=r_{t} \\
& y_{t}=\frac{z_{t}}{s_{t}} k_{t}^{\alpha} \ell_{t}^{1-\alpha} \\
& k_{t+1}=i_{t}+(1-\delta) k_{t} \\
& y_{t}=c_{t}+i_{t}+g_{t} \\
& s_{t}=\left(1-\phi_{p}\right) \tilde{p}_{t}^{-\theta}+\phi_{p}\left[\frac{\pi_{t}}{\bar{\pi}}\right]^{\theta} s_{t-1} \\
& d_{t}+\tau_{t}^{c} c_{t}+\tau_{t}^{k}\left(r_{t}-\delta\right) k_{t}+\tau_{t}^{\ell} w_{t} \ell_{t}=R_{t-1} d_{t-1} / \pi_{t}+g_{t} \\
& \ln \left[z_{t+1}\right]=\rho_{z} \ln \left[z_{t}\right]+\sigma_{z} \epsilon_{t+1}^{z} \\
& \ln \left[g_{t+1}^{c}\right]=\rho_{g} \ln \left[g_{t}^{c}\right]+\left(1-\rho_{g}\right) \ln \left[\bar{g}^{c}\right]+\sigma_{g} \epsilon_{t+1}^{g} \\
& y_{t}
\end{aligned}
$$


The system is closed with the rules for fiscal and monetary policy.

\section{The state-space representation of the model}

The first-order conditions of the model economy can be arranged in the following way:

$$
\mathrm{E}_{t} \mathcal{H}\left(e_{t+1}, e_{t}, x_{t+1}, x_{t} \mid \sigma\right)=0,
$$

where $y$ is a vector of co-state variables. The state variables are collected in $x$ :

$$
x_{t}:=\left[\begin{array}{l}
x_{1, t} \\
x_{2, t}
\end{array}\right]
$$

with vectors of endogenous state variables $x_{1, t}$, and exogenous state variables $x_{2, t}$ :

$$
x_{2, t+1}=\Lambda_{1} x_{2, t}+\Lambda_{2} \sigma \epsilon_{t+1},
$$

with matrices $\Lambda_{1}$ and $\Lambda_{2}$. The scalar $\sigma \geq 0$ is known.

With steady-state indexation, and consumption taxes as the fiscal-policy instrument, we define the following vectors and matrices (analogous vectors are defined in the other cases):

$$
\begin{aligned}
& x_{1, t}=\left[\begin{array}{llll}
k_{t} & s_{t} & d_{t-1} & R_{t-1}
\end{array}\right]^{\prime}, \\
& x_{2, t}=\left[\begin{array}{ll}
z_{t} & g_{t}
\end{array}\right]^{\prime} \text {, } \\
& e_{t}=\left[\begin{array}{llllllllllll}
y_{t} & R_{t} & d_{t} & \mathrm{mc}_{t} & c_{t} & \pi_{t} & \ell_{t} & r_{t} & w_{t} & \varsigma_{t} & x_{t}^{1} & \tau_{t}^{c}
\end{array}\right]^{\prime} \text {, } \\
& \Lambda_{1}=\left[\begin{array}{ll}
1 & 0 \\
0 & 1
\end{array}\right] \text {, } \\
& \Lambda_{3}=\left[\begin{array}{ccccc}
0 & 0 & 0 & \sigma_{z} & 0 \\
0 & 0 & 0 & 0 & \sigma_{g}
\end{array}\right]^{\prime} \text {. }
\end{aligned}
$$

\section{E Computation of conditional second moments}

The computation of conditional moments requires analytical formulas for multistep-ahead forecasts. Kim, Kim, Schaumburg, and Sims (2003) suggest that using the expressions of the full second-order approximation for the recursive calculation of these forecasts introduces spurious higher-order terms. This problem can be avoided by exploiting the linear (first-order) part of the solution.

Let $\hat{e}_{t}^{(2)}$ denote the full second-order solution, and $\hat{e}_{t}^{(1)}$ denote the linear part. We can write the system of solutions

$$
\begin{aligned}
& {\left[\begin{array}{c}
\hat{e}_{t}^{(2)} \\
\hat{e}_{t}^{(1)} \otimes \hat{e}_{t}^{(1)}
\end{array}\right]=M_{1}\left[\begin{array}{c}
\hat{x}_{t}^{(2)} \\
\hat{x}_{t}^{(1)} \otimes \hat{x}_{t}^{(1)}
\end{array}\right]+K_{1},} \\
& {\left[\begin{array}{c}
\hat{x}_{t+1}^{(2)} \\
\hat{x}_{t+1}^{(1)} \otimes \hat{x}_{t+1}^{(1)}
\end{array}\right]=M_{2}\left[\begin{array}{c}
\hat{x}_{t}^{(2)} \\
\hat{x}_{t}^{(1)} \otimes \hat{x}_{t}^{(1)}
\end{array}\right]+K_{2}+u_{t+1} .}
\end{aligned}
$$

Define

$$
X_{t}=\left(\begin{array}{c}
\hat{x}_{t}^{(2)} \\
\hat{x}_{t}^{(1)} \otimes \hat{x}_{t}^{(1)}
\end{array}\right),
$$




$$
Y_{t}=\left(\begin{array}{c}
\hat{e}_{t}^{(2)} \\
\hat{e}_{t}^{(1)} \otimes \hat{e}_{t}^{(1)}
\end{array}\right),
$$

Equations 39 and 38 can be re-written by repeated substitution as

$$
\begin{aligned}
& X_{t+k}=M_{2}^{k} X_{t}+\sum_{i=0}^{k-1} M_{2}^{i}\left(K_{2}+u_{t+k-i}\right), \\
& Y_{t+k}=M_{1} X_{t+k}+K_{1}=K_{1}+M_{1} M_{2}^{k} X_{t}+\sum_{i=0}^{k-1} M_{1} M_{2}^{i}\left(K_{2}+u_{t+k-i}\right) .
\end{aligned}
$$

The expectation conditional on an initial state vector takes the form

$$
E\left(Y_{t+k} \mid X_{t}\right)=K_{1}+M_{1} M_{2}^{k} X_{t}+\sum_{i=0}^{k-1} M_{1} M_{2}^{i} K_{2} .
$$

The conditional variance can be computed from

$$
\begin{aligned}
Y_{t+k}-E\left(Y_{t+k} \mid X_{t}\right) & =\sum_{i=0}^{k-1} M_{1} M_{2}^{i} u_{t+k-i}, \\
\operatorname{Cov}\left(Y_{t+k} \mid X_{t}\right) & =E\left\{\left[Y_{t+k}-E\left(Y_{t+k} \mid X_{t}\right)\right]\left[Y_{t+k}-E\left(Y_{t+k} \mid X_{t}\right)\right]^{\prime} \mid X_{t}\right\}, \\
& =\sum_{i=0}^{k-1} M_{1} M_{2}^{i} \Sigma_{u}\left(M_{1} M_{2}^{i}\right)^{\prime},
\end{aligned}
$$

where $\Sigma_{u}:=E\left(u_{t} u_{t}^{\prime}\right)$. From Paustian (2003), we know that $u_{t}$ takes the form

$$
u_{t}=\left(\begin{array}{c}
\sigma N \epsilon_{t} \\
\sigma^{2}(N \otimes N)\left(\operatorname{vec}(I)-\epsilon_{t} \otimes \epsilon_{t}\right)
\end{array}\right) .
$$

Marzo, Strid, and Zagaglia (2006) show that the variance matrix of $u_{t}$ is

$$
\mathrm{E} u_{t} u_{t}^{\prime}=\left(\begin{array}{cc}
\sigma^{2} N N^{\prime} & 0 \\
0 & 2 \sigma^{4}(N \otimes N) \operatorname{vec}(I) \operatorname{vec}(I)^{\prime}(N \otimes N)^{\prime}
\end{array}\right) .
$$




\section{References}

Anderson, G., A. T. Levin, and E. Swanson (2004): "Higher-Order Perturbation Solutions to Dynamic, Discrete-Time Rational Expectations Models," unpublished manuscript, Federal Reserve Board.

Bayoumi, T., D. Laxton, and P. Pesenti (2004): "Benefits and Spillovers of Greater Competition in Europe," NBER Working Paper, 10416.

Calvo, G. (1983): "Staggered Prices in a Utility Maximizing Framework," Journal of Monetary Economics, 12(3), 383-398.

Christiano, L., M. Eichenbaum, and C. Evans (2005): "Nominal Rigidites and the Dynamic Effect of a Shock to Monetary Policy," Journal of Political Economy, 113(1), 1-45.

Correia, I., J. P. Nicolini, and P. Teles (2003): "Optimal Fiscal and Monetary Policy: Equivalence Results," CEPR Discussion Paper, 3730.

Kim, J., And S. H. Kim (2003): "Welfare Effects of Tax Policy in Open Economies: Stabilization and Cooperation," unpublished manuscript, Tufts University.

Kim, J., S. H. Kim, E. Schaumburg, and C. Sims (2003): "Calculating and Using Second Order Accurate Solutions of Discrete Time Dynamic Equilibrium Models," unpublished manuscript, Princeton University.

Kollmann, R. (2006): "Welfare Maximizing Fiscal and Monetary Policy Rules," forthcoming in Macroeconomic Dynamics.

Leeper, E. (1991): "Equilibria under 'Active' and 'Passive' Monetary and Fiscal Policies," Journal of Monetary Economics, 27(2), 129-147.

Marzo, M. (2003): "Accurate Welfare and Monetary Rules in a Large-Scale Dynamic Model," unpublished manuscript, Università di Bologna.

Marzo, M., I. Strid, and P. Zagaglia (2006): "Optimal Opportunistic Monetary Policy in the New-Keynesian Model," unpublished manuscript, Stockholm University.

PAPPA, E. (2004): "Do the ECB and the Fed Really Need to Cooperate? Optimal Monetary Policy in a Two-Country World," Journal of Monetary Economics, 51(4), 753-779.

Paustian, M. (2003): "Gains from Second-Order Approximations," unpublished manuscript, University of Bonn.

Ramsey, F. P. (1927): "A Contribution to the Theory of Taxation," Economic Journal, 37(145), $47-61$.

Renström, T. I. (2006): "Dynamic Taxation and Equivalent Tax Systems," unpublished manuscript, University of Birmingham.

Schmitt-Grohé, S., And M. Uribe (2004): "Solving Dynamic General Equilibrium Models Using a Second-Order Approximation to the Policy Function," Journal of Economic Dynamics and Control, 28(3), 755-775.

(2005a): "Optimal Fiscal and Monetary Policy in a Medium-Scale Macroeconomic Model," in NBER Macroeconomics Annual 2005, ed. by M. Gertler, and K. Rogoff. MIT Press: Cambridge MA.

(2005b): "Optimal Operational Monetary Policy in the Christiano-Eichenbaum-Evans Model of the U.S. Business Cycle," NBER Working Paper, 11417. 
(2006): "Optimal Simple and Implementable Monetary and Fiscal Rules," forthcoming in the Journal of Monetary Economics.

TAYlor, J. B. (1993): "Discretion versus Policy Rules in Practice," Carnegie-Rochester Conference Series, 39, 195-214. 


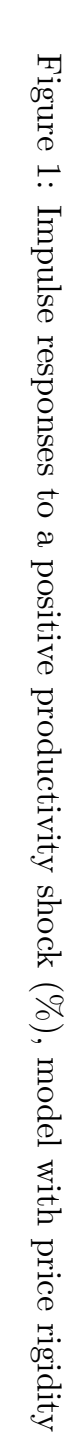
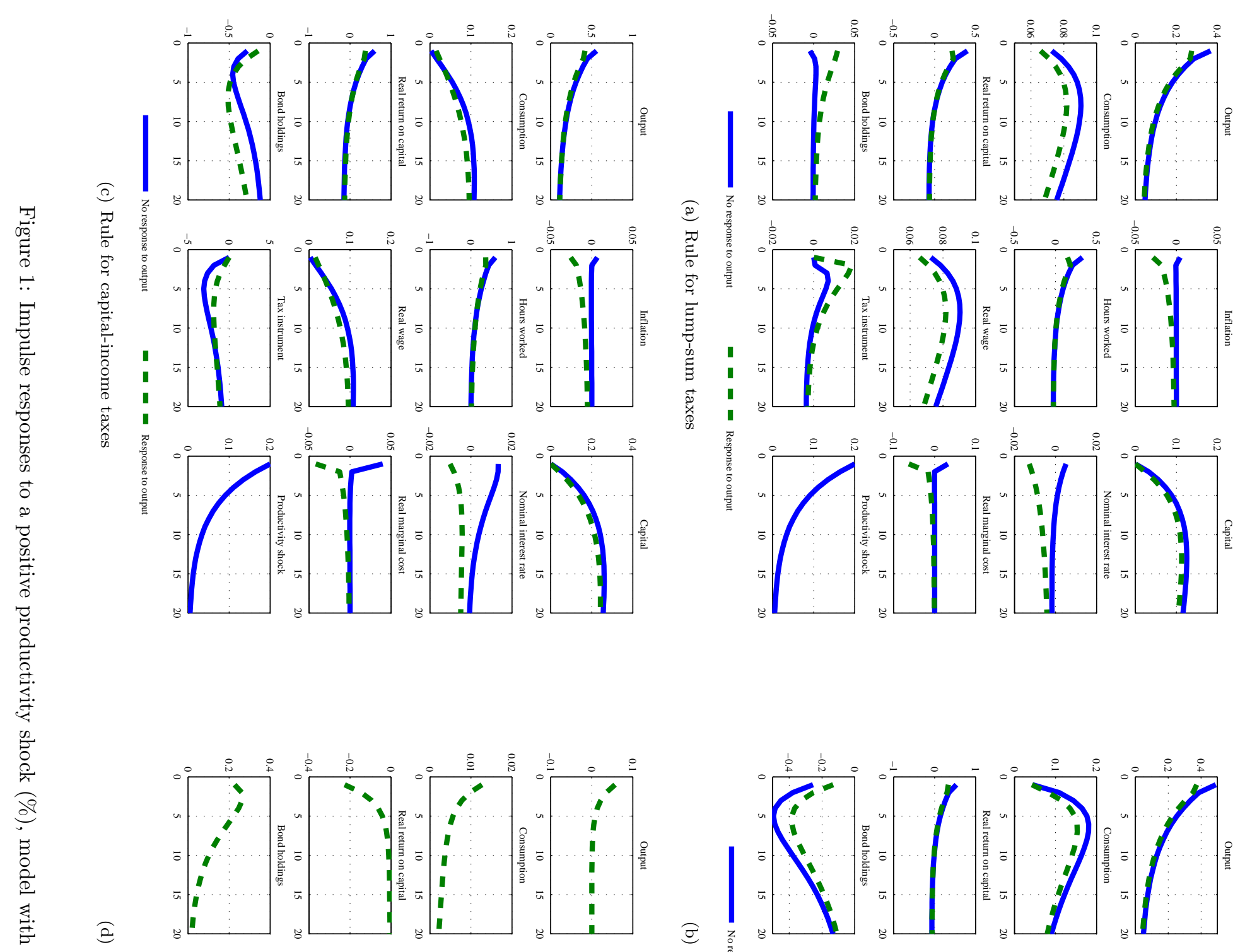

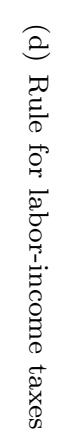
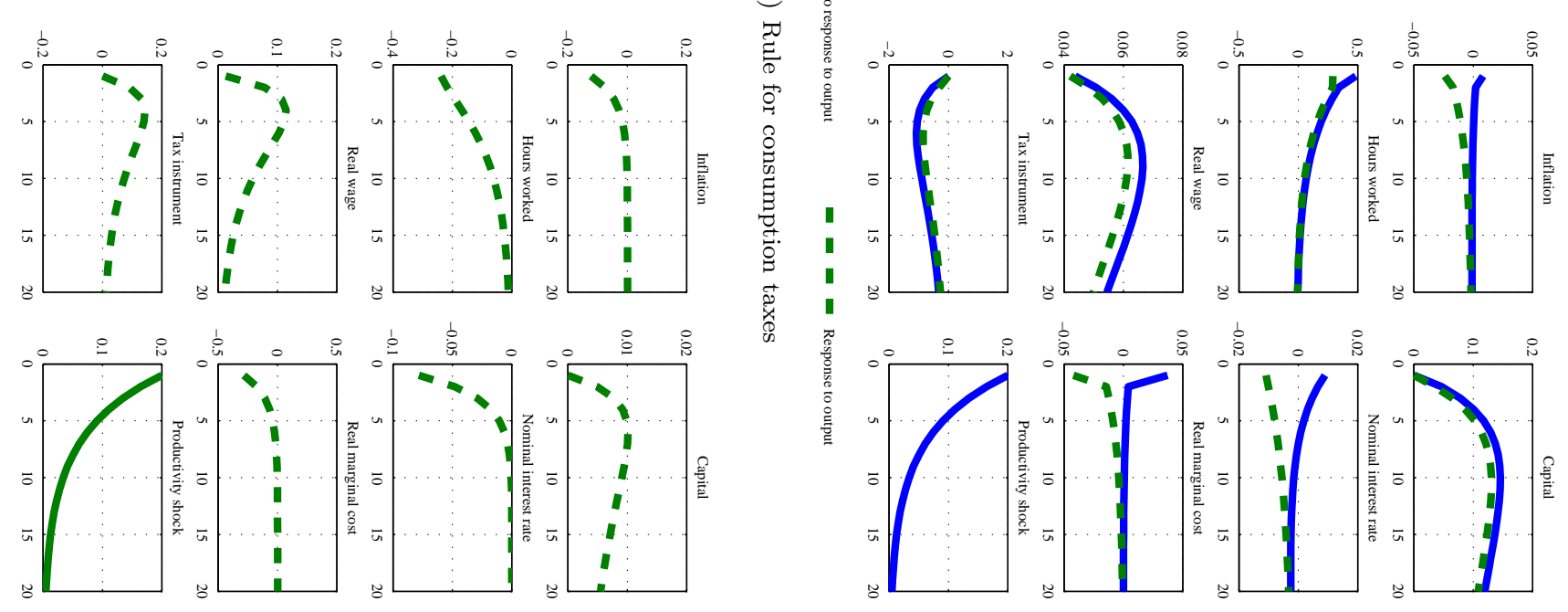
Figure 2: Variance of inflation (\%) as a function of $\alpha_{y}$, model with price rigidity

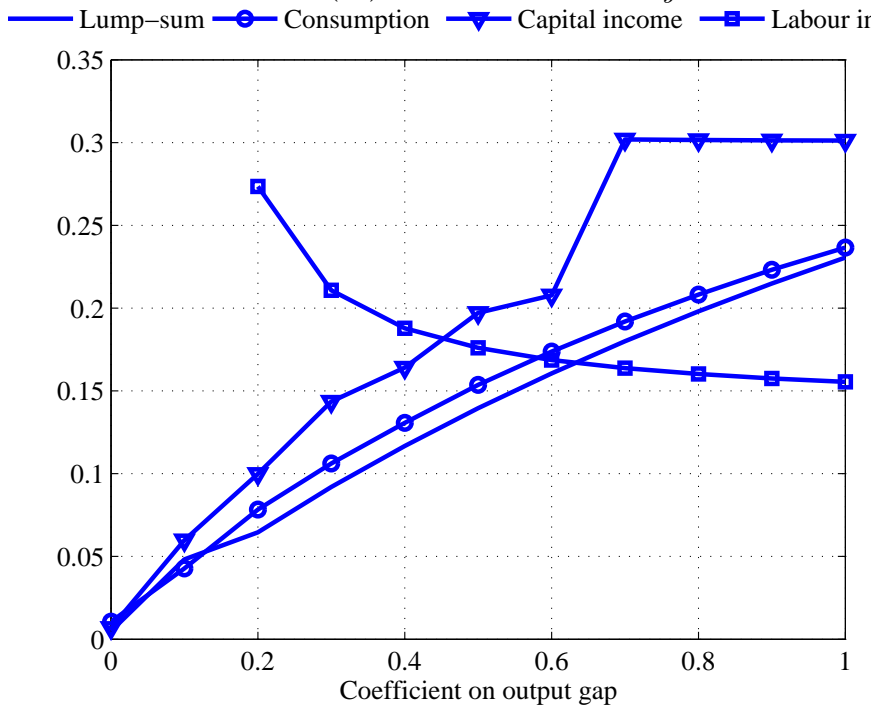

Legend: For a each value of $\alpha_{y}$, we search for the remaining parameters of the policy rules that maximize $\mathcal{W}_{0}$. This figure reports the percentage variance of inflation at each (constrained) welfare-maximizing combination of parameters. 

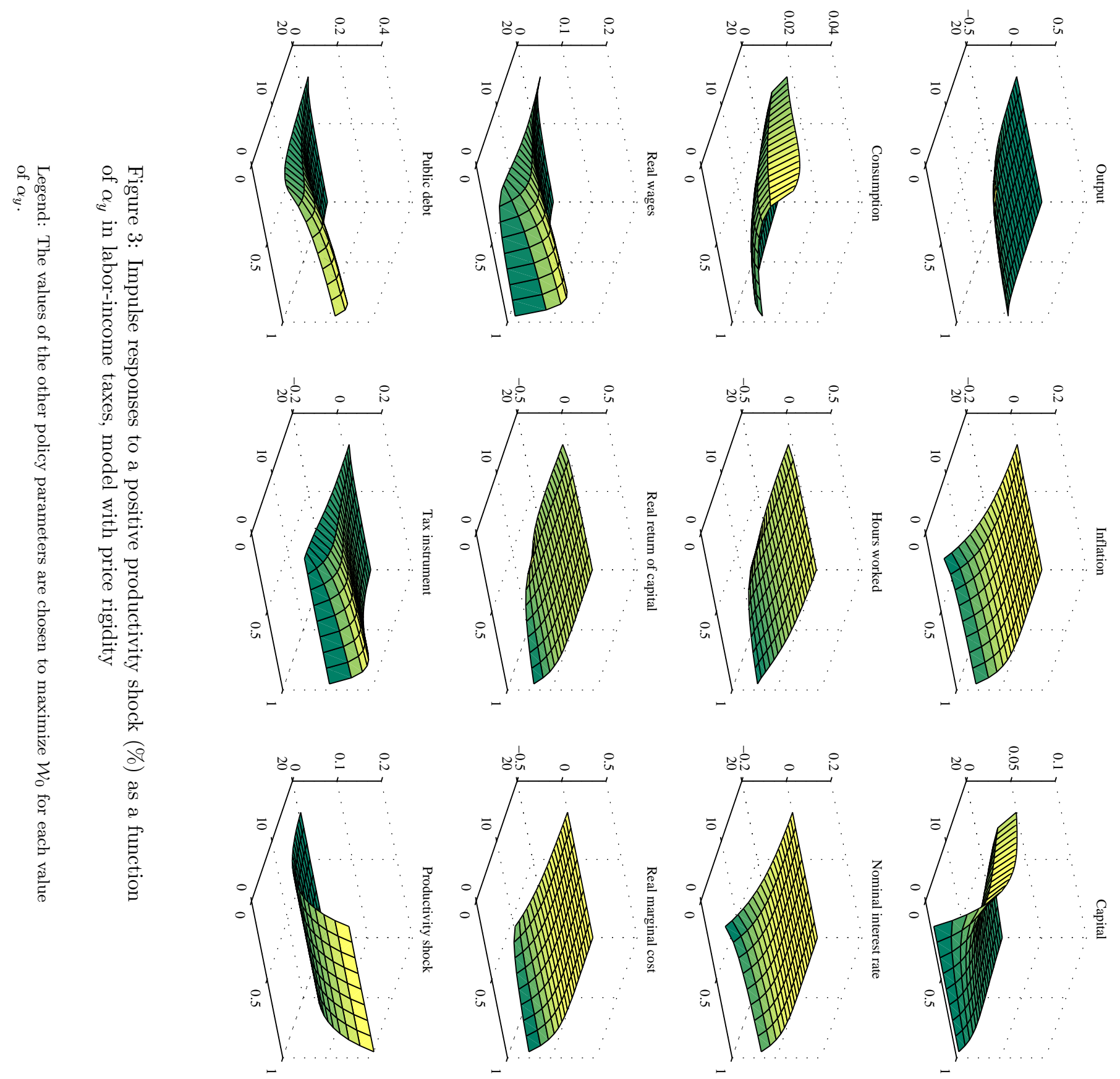
Figure 4: Percentage change in welfare costs from policy mistakes on $\alpha_{y}$, model with price rigidity

(4.1) Lump-sum taxes

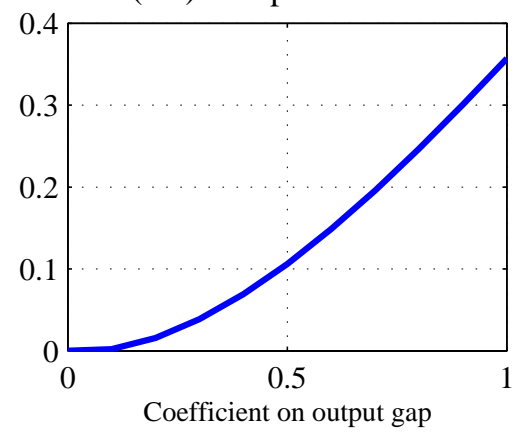

(4.3) Capital-income taxes

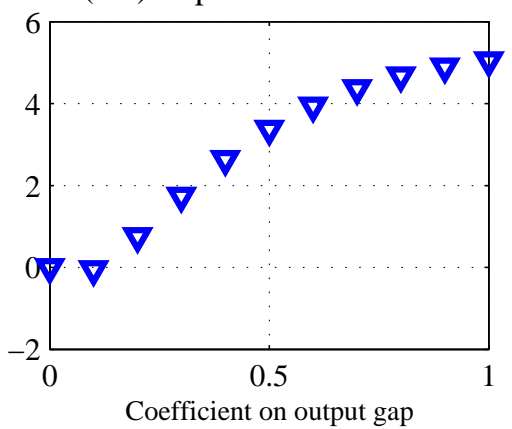

(4.2) Consumption taxes

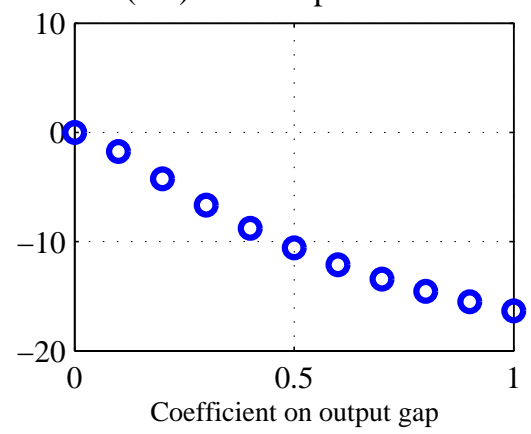

(4.4) Labour-income taxes

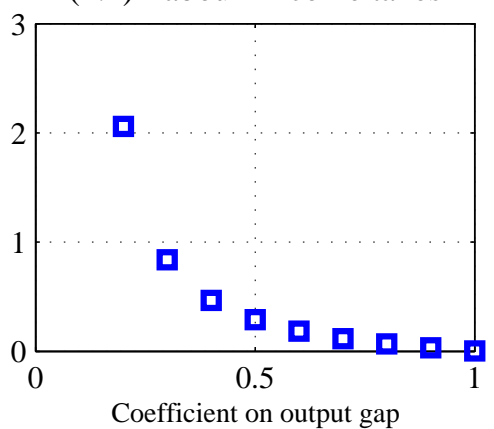

Legend: Denote by a star the parameter values that maximize $\mathcal{W}_{0}(\cdot)$ over the full grid $\left\{\alpha_{\pi}, \alpha_{y}, \alpha_{R}, \psi_{1}\right\}$. The corresponding conditional welfare cost is $\Phi_{c}^{\iota}\left(\alpha_{\pi}^{*}, \alpha_{y}^{*}, \alpha_{R}^{*}, \psi_{1}^{*}\right)$. For a given $\alpha_{y}$, this figure plots

$$
100 \times\left[\Phi_{c}^{\iota}\left(\alpha_{\pi}^{*}, \alpha_{y}, \alpha_{R}^{*}, \psi_{1}^{*}\right)-\Phi_{c}^{\iota}\left(\alpha_{\pi}^{*}, \alpha_{y}^{*}, \alpha_{R}^{*}, \psi_{1}^{*}\right)\right] / \Phi_{c}^{\iota}\left(\alpha_{\pi}^{*}, \alpha_{y}^{*}, \alpha_{R}^{*}, \psi_{1}^{*}\right) .
$$


Figure 5: Percentage change in welfare costs from welfare-maximizing policy rules as a function of $\alpha_{y}$, model with price rigidity

(5.1) Lump-sum taxes

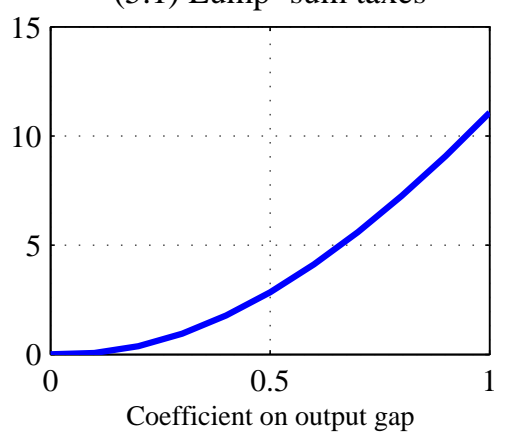

(5.3) Capital-income taxes

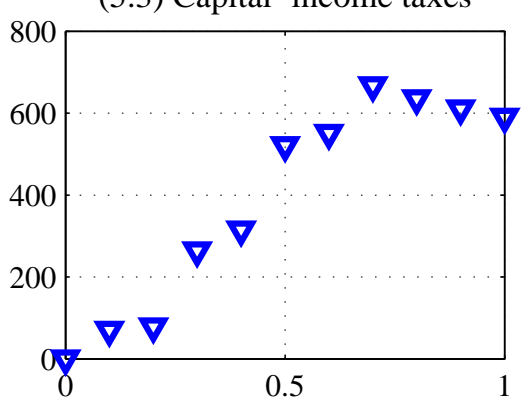

Coefficient on output gap
(5.2) Consumption taxes

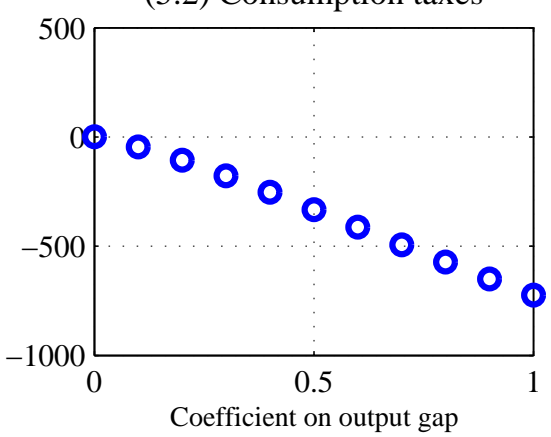

(5.4) Labour-income taxes

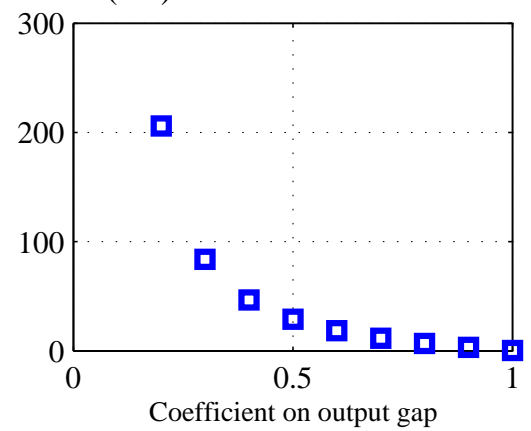

Legend: Denote by a star the unconstrained parameter values that maximize $\mathcal{W}_{0}(\cdot)$ over the full grid $\left\{\alpha_{\pi}, \alpha_{y}, \alpha_{R}, \psi_{1}\right\}$. The corresponding conditional welfare cost is $\Phi_{c}^{\iota}\left(\alpha_{\pi}^{*}, \alpha_{y}^{*}, \alpha_{R}^{*}, \psi_{1}^{*}\right)$. For a given $\alpha_{y}$, a new set of welfare-maximizing parameters $\left\{\bar{\alpha}_{\pi}, \alpha_{y}, \bar{\alpha}_{R}, \bar{\psi}_{1}\right\}$ is computed with $\Phi_{c}^{\iota}\left(\bar{\alpha}_{\pi}, \alpha_{y}, \bar{\alpha}_{R}, \bar{\psi}_{1}\right)$. This figure plots

$$
100 \times\left[\Phi_{c}^{\iota}\left(\bar{\alpha}_{\pi}, \alpha_{y}, \bar{\alpha}_{R}, \bar{\psi}_{1}\right)-\Phi_{c}^{\iota}\left(\alpha_{\pi}^{*}, \alpha_{y}^{*}, \alpha_{R}^{*}, \psi_{1}^{*}\right)\right] / \Phi_{c}^{\iota}\left(\alpha_{\pi}^{*}, \alpha_{y}^{*}, \alpha_{R}^{*}, \psi_{1}^{*}\right) .
$$


Figure 6: Percentage change in welfare costs from policy mistakes on $\psi_{1}$, model with price rigidity
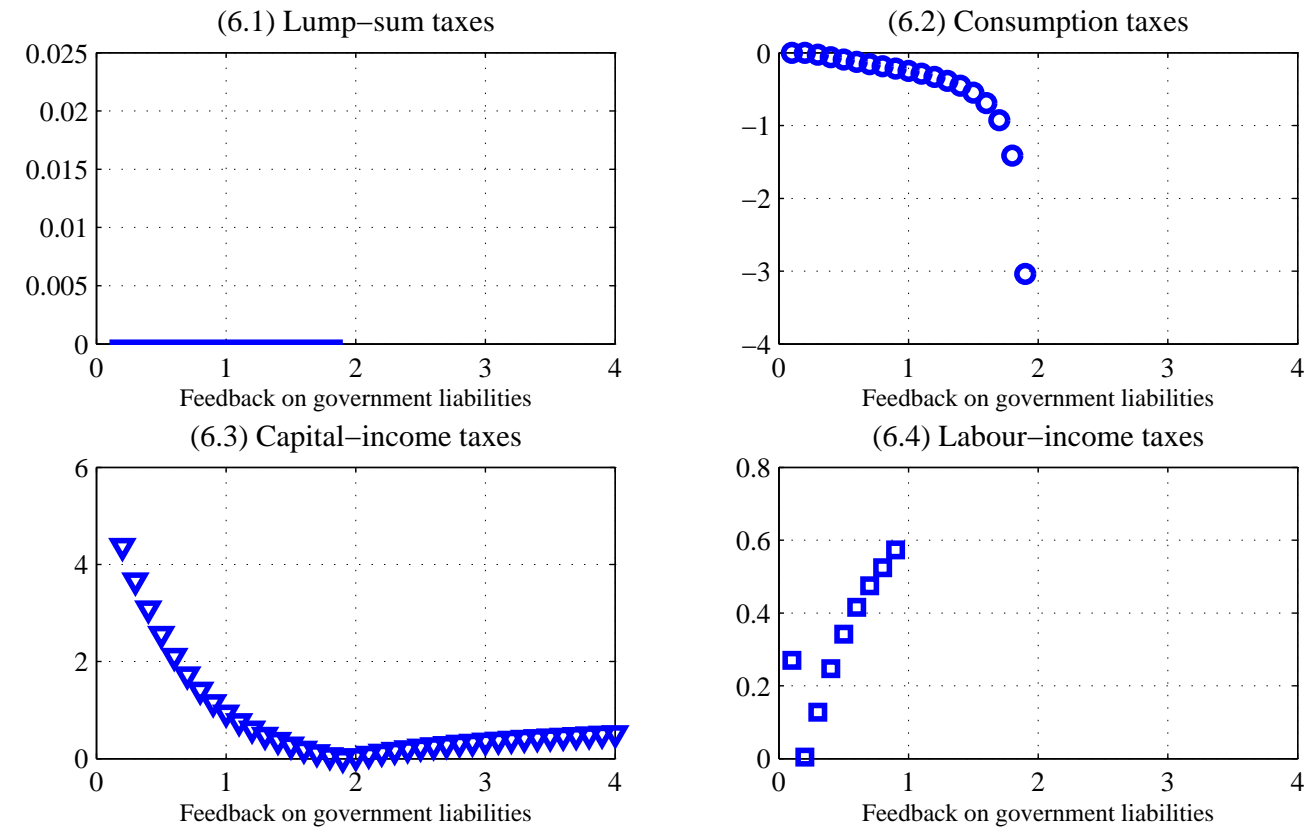

Legend: Denote by a star the parameter values that maximize $\mathcal{W}_{0}(\cdot)$ over the full grid $\left\{\alpha_{\pi}, \alpha_{y}, \alpha_{R}, \psi_{1}\right\}$. The corresponding conditional welfare cost is $\Phi_{c}^{\iota}\left(\alpha_{\pi}^{*}, \alpha_{y}^{*}, \alpha_{R}^{*}, \psi_{1}^{*}\right)$. For a given $\psi_{1}$, this figure plots

$$
100 \times\left[\Phi_{c}^{\iota}\left(\alpha_{\pi}^{*}, \alpha_{y}^{*}, \alpha_{R}^{*}, \psi_{1}\right)-\Phi_{c}^{\iota}\left(\alpha_{\pi}^{*}, \alpha_{y}^{*}, \alpha_{R}^{*}, \psi_{1}^{*}\right)\right] / \Phi_{c}^{\iota}\left(\alpha_{\pi}^{*}, \alpha_{y}^{*}, \alpha_{R}^{*}, \psi_{1}^{*}\right) .
$$


Figure 7: Percentage change in welfare costs from policy mistakes on $\alpha_{R}$, model with price rigidity
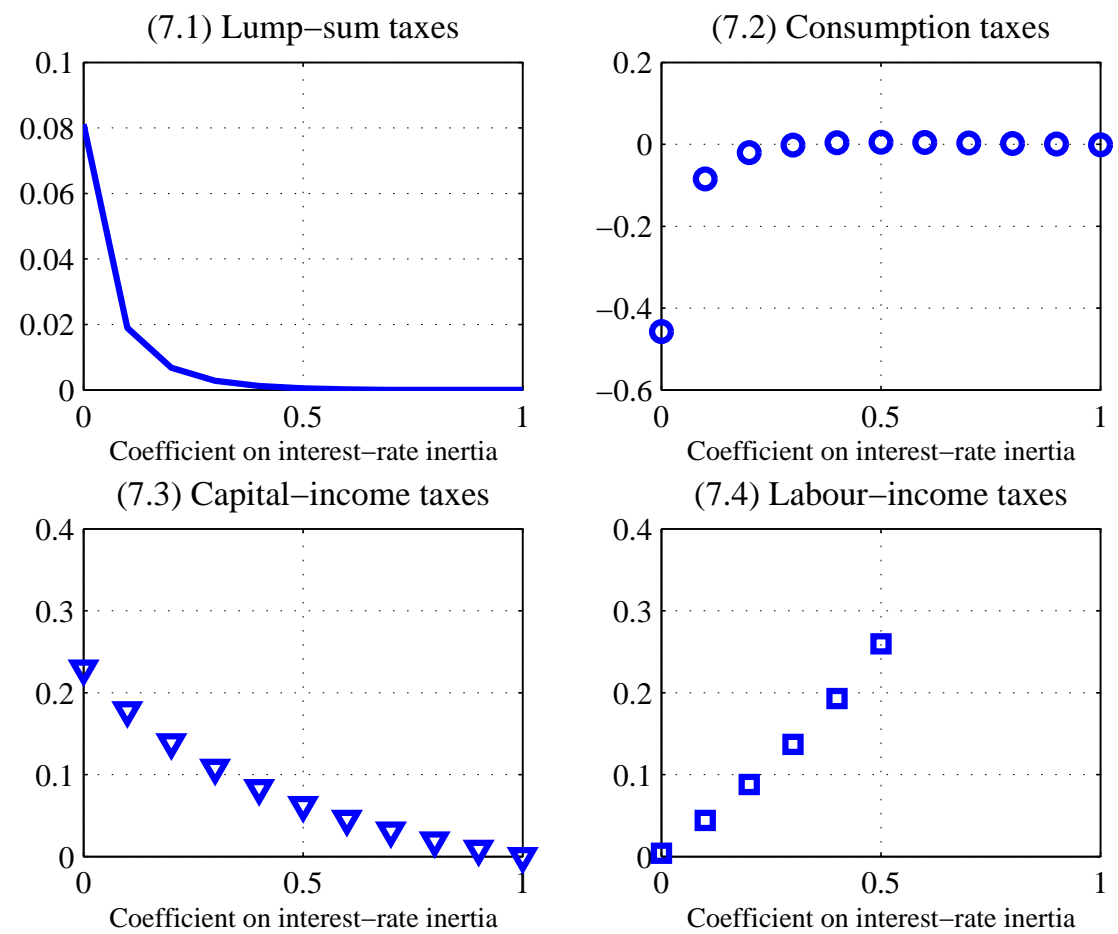

Legend: Denote by a star the parameter values that maximize $\mathcal{W}_{0}(\cdot)$ over the full grid $\left\{\alpha_{\pi}, \alpha_{y}, \alpha_{R}, \psi_{1}\right\}$. The corresponding conditional welfare cost is $\Phi_{c}^{\iota}\left(\alpha_{\pi}^{*}, \alpha_{y}^{*}, \alpha_{R}^{*}, \psi_{1}^{*}\right)$. For a given $\alpha_{R}$, this figure plots

$$
100 \times\left[\Phi_{c}^{\iota}\left(\alpha_{\pi}^{*}, \alpha_{y}^{*}, \alpha_{R}, \psi_{1}^{*}\right)-\Phi_{c}^{\iota}\left(\alpha_{\pi}^{*}, \alpha_{y}^{*}, \alpha_{R}^{*}, \psi_{1}^{*}\right)\right] / \Phi_{c}^{\iota}\left(\alpha_{\pi}^{*}, \alpha_{y}^{*}, \alpha_{R}^{*}, \psi_{1}^{*}\right) .
$$


Figure 8: Impulse responses to a positive productivity shock (\%) with rule for consumption taxes, model with flexible prices
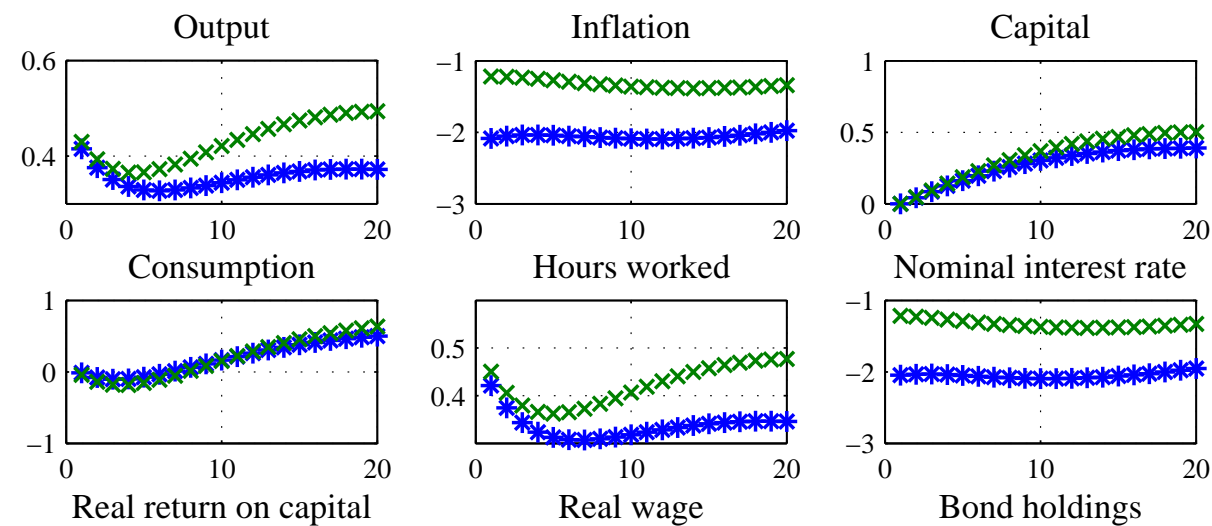

Nominal interest rate
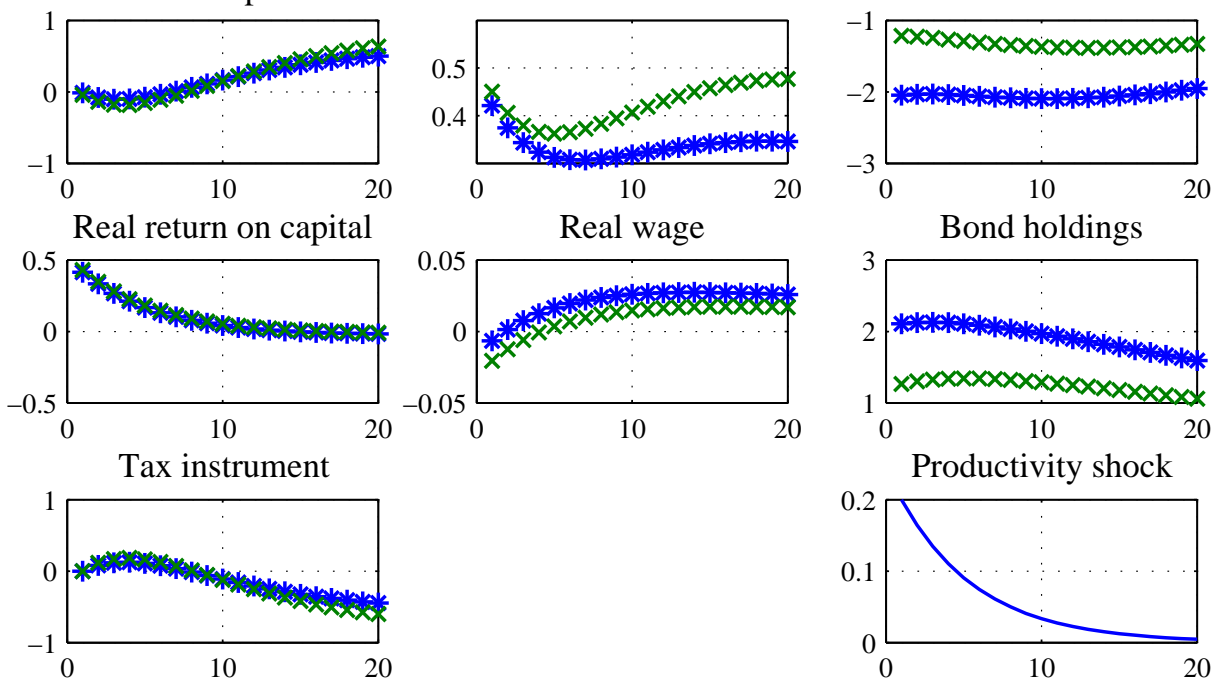

* $\quad \psi_{1} \in[0,1.9] \quad \times \quad \psi_{1} \in[2,4]$

Legend: The parameter values of the underlying policy rules are chosen to maximize conditional welfare. Passive fiscal policy restricts $\psi_{1} \in[0,1.9]$, whereas for active fiscal policy $\psi_{1} \in[2,4]$. The optimal rules with active fiscal policy are: $\hat{R}_{t}=1.1 \hat{\pi}_{t}+0.3 \hat{y}_{t}$ and $\tau_{t}^{c}=0.571+2.0\left(l_{t-1}-l\right)$. 
Figure 9: Percentage change in welfare costs from policy mistakes on $\psi_{1}$, model with flexible prices
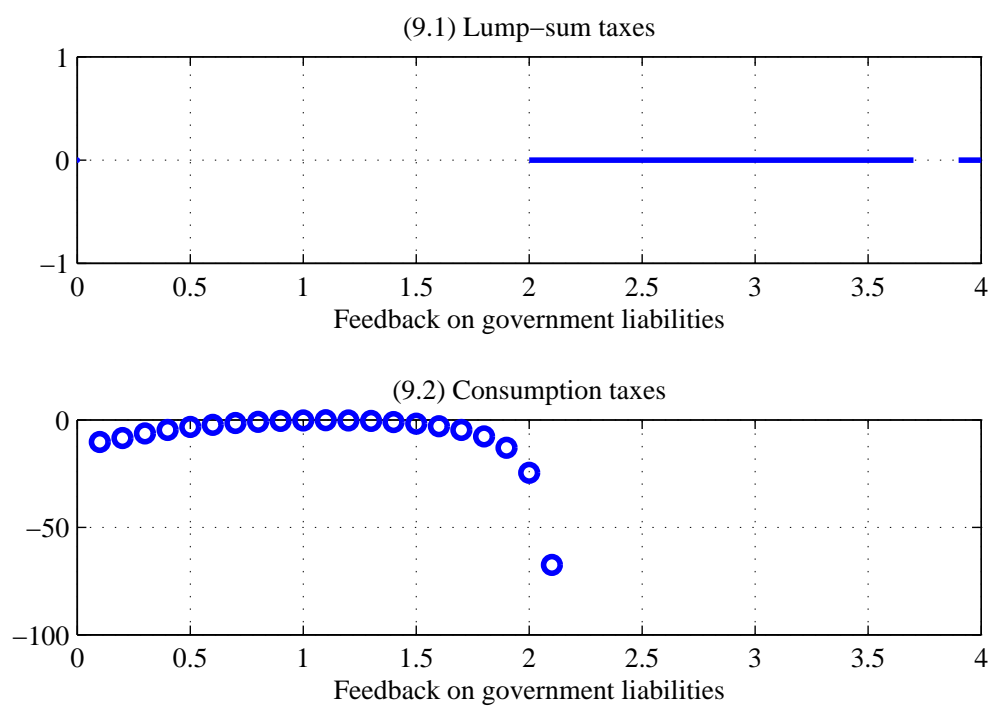

(9.3) Capital-income taxes

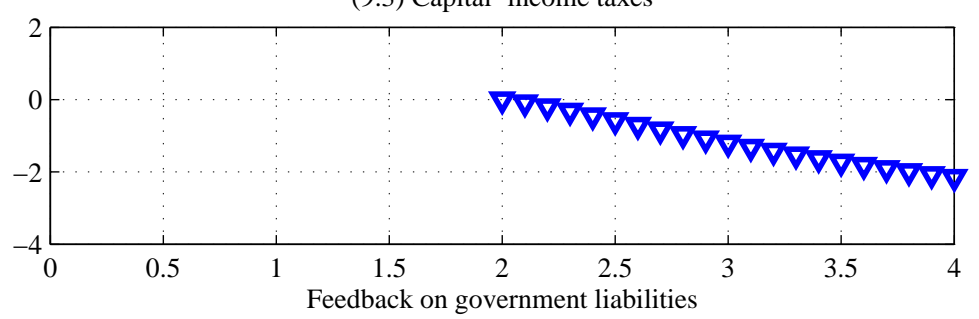

Legend: Denote by a star the parameter values that maximize $\mathcal{W}_{0}(\cdot)$ over the full grid $\left\{\alpha_{\pi}, \alpha_{y}, \alpha_{R}, \psi_{1}\right\}$. The corresponding conditional welfare cost is $\Phi_{c}^{\iota}\left(\alpha_{\pi}^{*}, \alpha_{y}^{*}, \alpha_{R}^{*}, \psi_{1}^{*}\right)$. For a given $\psi_{1}$, this figure plots

$$
100 \times\left[\Phi_{c}^{\iota}\left(\alpha_{\pi}^{*}, \alpha_{y}^{*}, \alpha_{R}^{*}, \psi_{1}\right)-\Phi_{c}^{\iota}\left(\alpha_{\pi}^{*}, \alpha_{y}^{*}, \alpha_{R}^{*}, \psi_{1}^{*}\right)\right] / \Phi_{c}^{\iota}\left(\alpha_{\pi}^{*}, \alpha_{y}^{*}, \alpha_{R}^{*}, \psi_{1}^{*}\right) .
$$




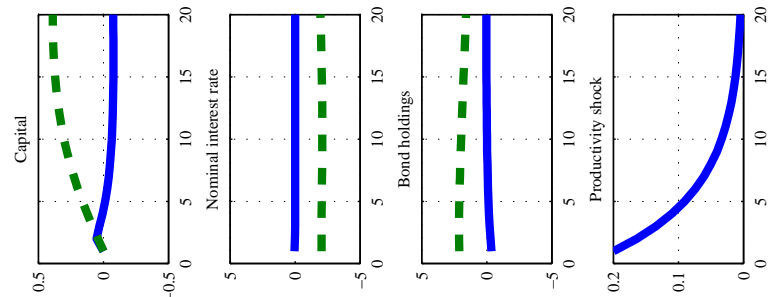

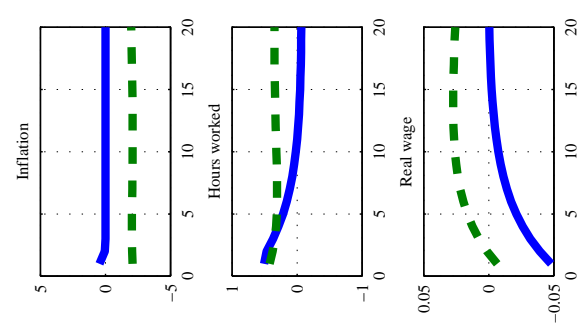

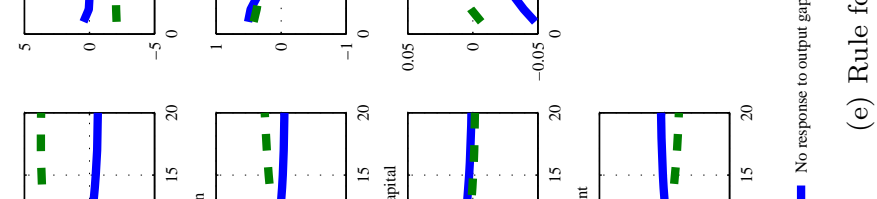
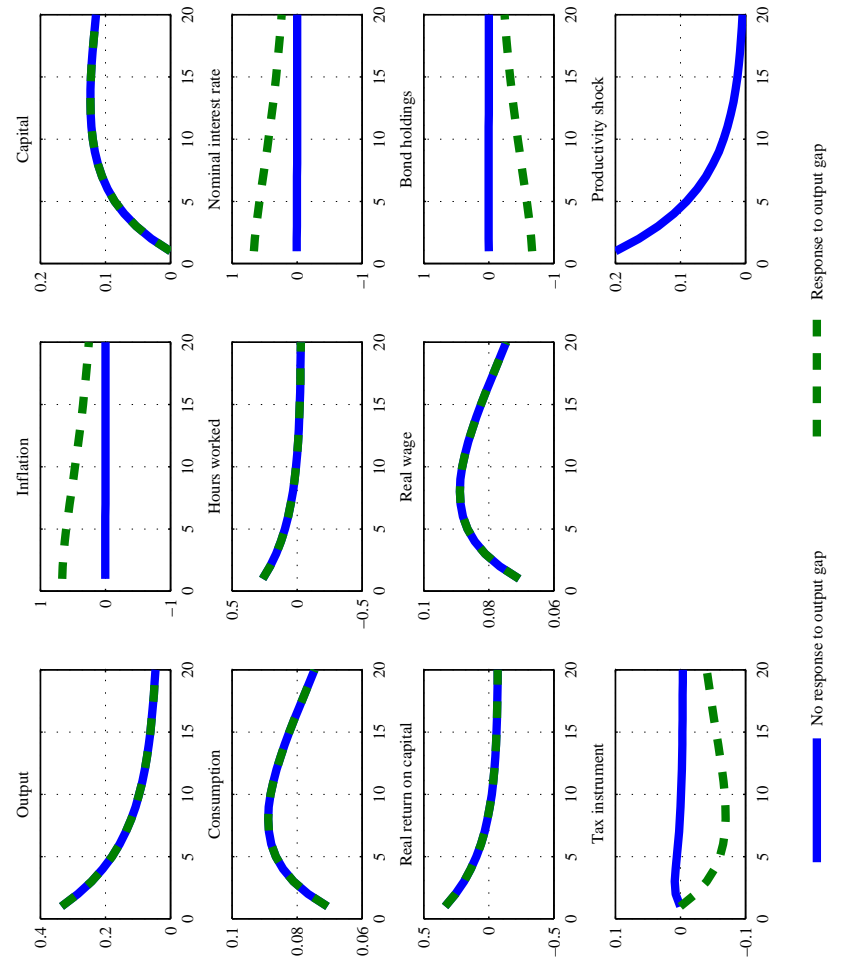
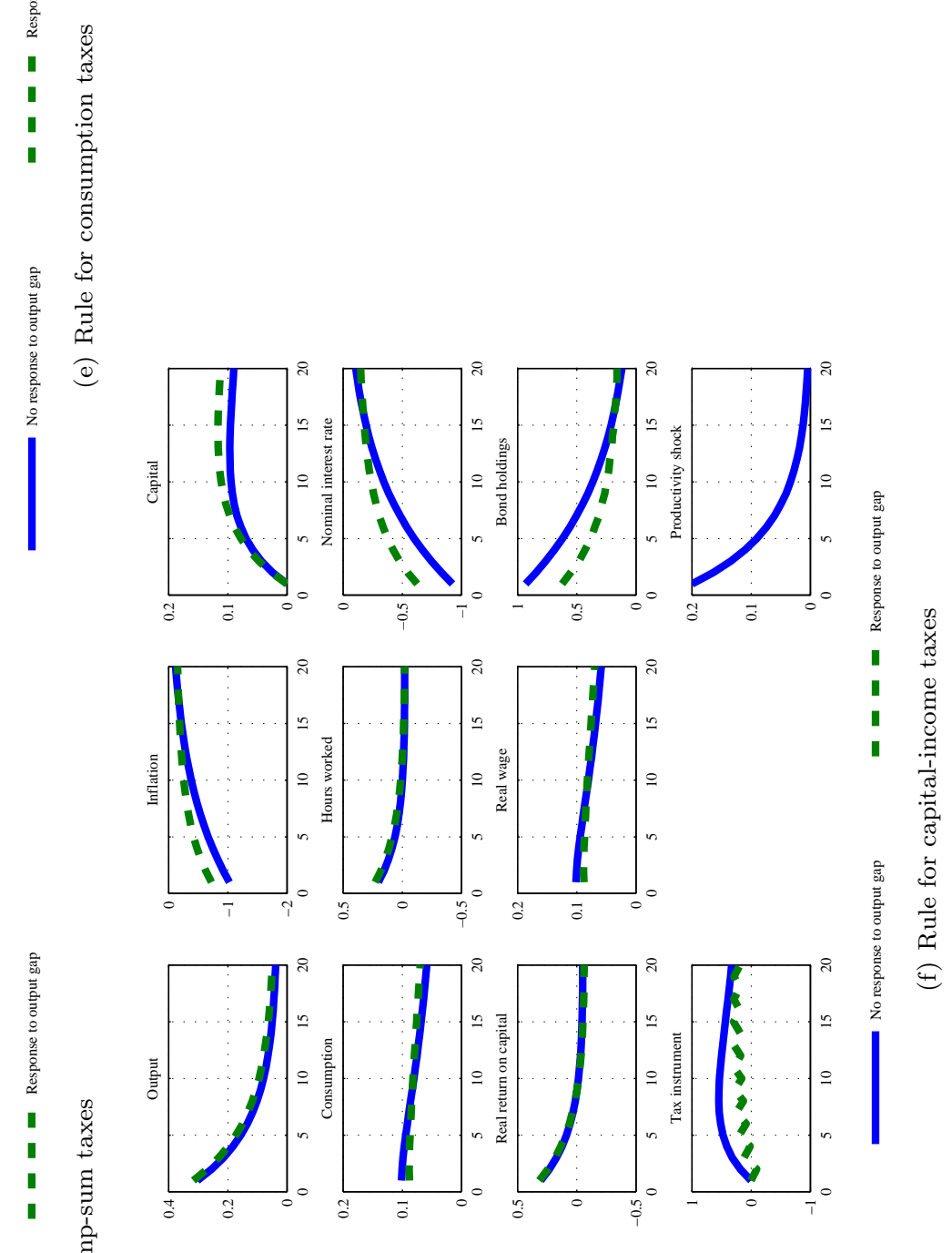

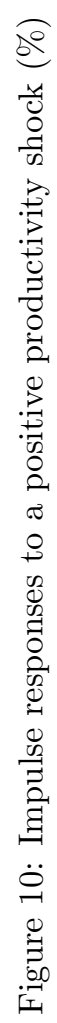


Figure 11: Percentage change in welfare costs from policy mistakes on $\alpha_{y}$, model with flexible prices
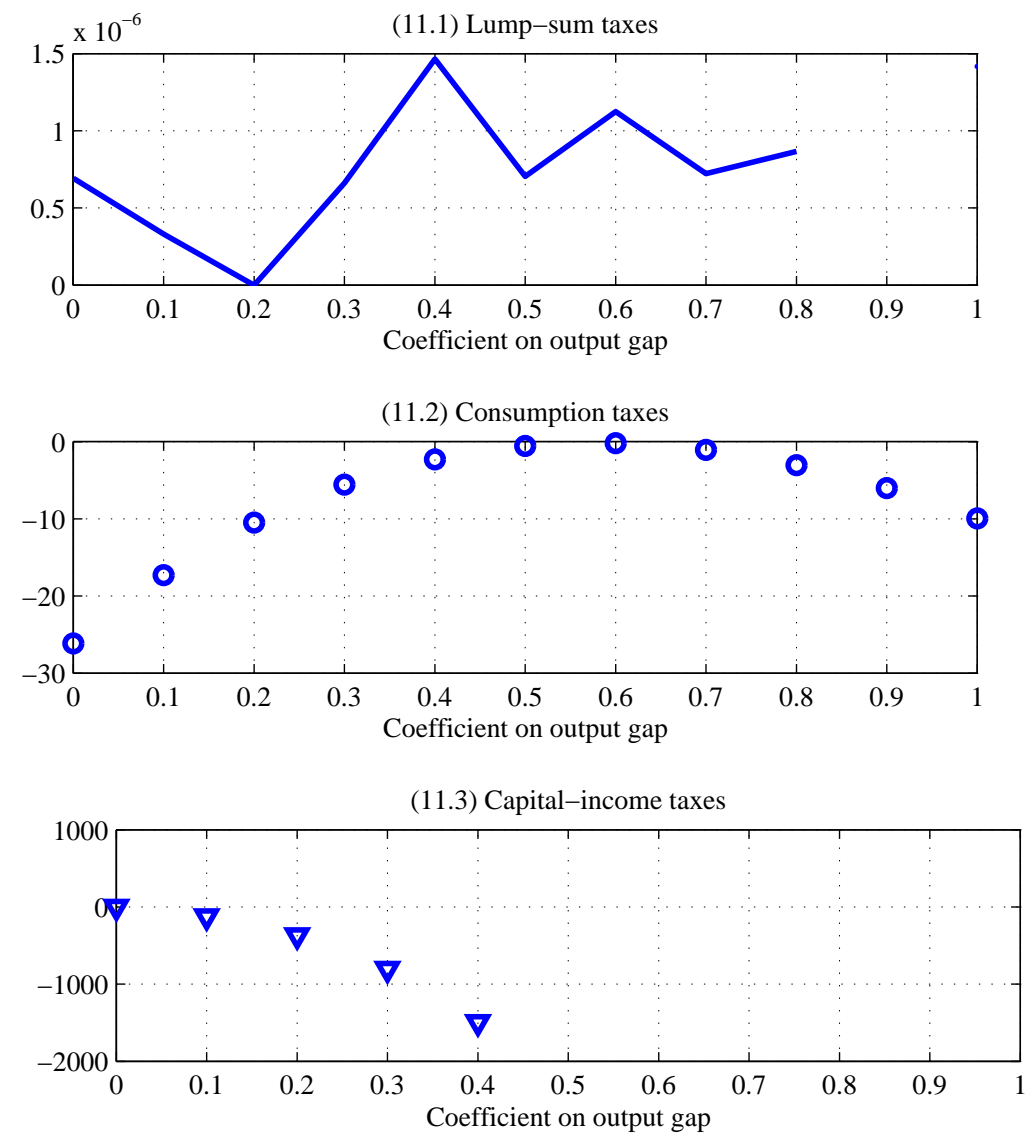

Legend: Denote by a star the parameter values that maximize $\mathcal{W}_{0}(\cdot)$ over the full grid $\left\{\alpha_{\pi}, \alpha_{y}, \alpha_{R}, \psi_{1}\right\}$. The corresponding conditional welfare cost is $\Phi_{c}^{\iota}\left(\alpha_{\pi}^{*}, \alpha_{y}^{*}, \alpha_{R}^{*}, \psi_{1}^{*}\right)$. For a given $\alpha_{y}$, this figure plots

$$
100 \times\left[\Phi_{c}^{\iota}\left(\alpha_{\pi}^{*}, \alpha_{y}, \alpha_{R}^{*}, \psi_{1}^{*}\right)-\Phi_{c}^{\iota}\left(\alpha_{\pi}^{*}, \alpha_{y}^{*}, \alpha_{R}^{*}, \psi_{1}^{*}\right)\right] / \Phi_{c}^{\iota}\left(\alpha_{\pi}^{*}, \alpha_{y}^{*}, \alpha_{R}^{*}, \psi_{1}^{*}\right) .
$$


Figure 12: Percentage change in welfare costs from policy mistakes on $\alpha_{R}$, model with flexible prices

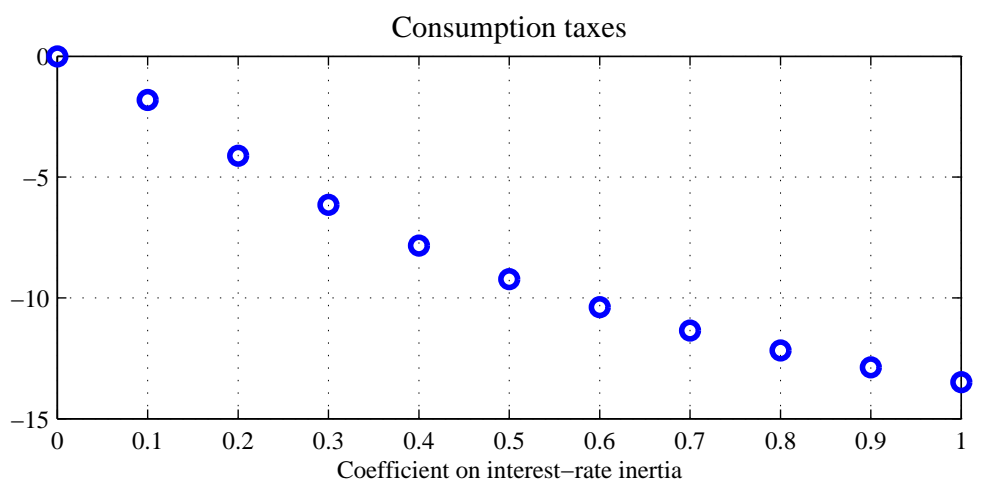

Legend: Denote by a star the parameter values that maximize $\mathcal{W}_{0}(\cdot)$ over the full grid $\left\{\alpha_{\pi}, \alpha_{y}, \alpha_{R}, \psi_{1}\right\}$. The corresponding conditional welfare cost is $\Phi_{c}^{\iota}\left(\alpha_{\pi}^{*}, \alpha_{y}^{*}, \alpha_{R}^{*}, \psi_{1}^{*}\right)$. For a given $\alpha_{R}$, this figure plots

$$
100 \times\left[\Phi_{c}^{\iota}\left(\alpha_{\pi}^{*}, \alpha_{y}^{*}, \alpha_{R}, \psi_{1}^{*}\right)-\Phi_{c}^{\iota}\left(\alpha_{\pi}^{*}, \alpha_{y}^{*}, \alpha_{R}^{*}, \psi_{1}^{*}\right)\right] / \Phi_{c}^{\iota}\left(\alpha_{\pi}^{*}, \alpha_{y}^{*}, \alpha_{R}^{*}, \psi_{1}^{*}\right) .
$$


Table 1: Calibration of the model

\begin{tabular}{lcc}
\hline \hline Description & Parameter & Value \\
\hline Subjective discount factor & $\beta$ & 0.9948 \\
Weight on disutility from work & $\gamma$ & 1 \\
Elasticity of substitution of intermediate goods & $\theta$ & 5 \\
Rate of capital depreciation & $\delta$ & $1.1^{(1 / 4)}-1$ \\
Capital elasticity of intermediate output & $\alpha$ & 0.4 \\
Fraction of firms not setting prices optimally & $\phi_{p}$ & $2 / 3$ \\
Steady-state inflation & $\bar{\pi}$ & $1.04^{(1 / 4)}$ \\
\hline Persistence of productiviy shock & $\rho_{z}$ & 0.92 \\
Standard dev. of productivity shock & $\sigma_{z}$ & 0.01 \\
\hline Steady-state average consumption taxes & $\bar{\tau}^{c}$ & 0.12 \\
Steady-state average capital-income taxes & $\bar{\tau}^{k}$ & 0.36 \\
Steady-state average labor-income taxes & $\bar{\tau}^{\ell}$ & 0.3168 \\
\hline Steady state ratio of gov. transfers to output & $\overline{t r} / \bar{y}$ & 0.1005 \\
Steady state ratio of gov. consumption to output & $\bar{g}^{c} / \bar{y}$ & 0.15 \\
Persistence of government spending shock & $\rho_{g}$ & 0.90 \\
Standard dev. of government spending shock & $\sigma_{g}$ & 0.01 \\
\hline \hline
\end{tabular}


Table 2: Optimized policy rules with price rigidity

\begin{tabular}{lcccccccc}
\hline \hline & \multicolumn{6}{c}{ [a] Fully optimized monetary-policy rules } \\
\cline { 2 - 9 } & $\alpha_{\pi}$ & $\alpha_{y}$ & $\alpha_{R}$ & $\psi_{1}$ & $\mathcal{W}_{0}^{\iota}$ & $\%_{c}^{\iota}$ & $\% \Delta_{E}^{\iota}$ & $\% \Delta_{V}^{\iota}$ \\
\cline { 2 - 8 } & 1.1 & 0.0 & 0.9 & 0.6 & 65.3633 & 6.14 & -9.05 & 13.930 \\
Lump-sum taxes* & 1.1 & 0.0 & 0.5 & 0.2 & -54.4477 & -0.002 & -16.89 & 13.931 \\
Consumption taxes & 2.0 & 0.0 & 1.0 & 1.9 & -54.4607 & 0.004 & -16.18 & 13.931 \\
Lapital-income taxes & 1.1 & 1.0 & 0.0 & 0.2 & -54.4627 & 0.005 & -16.17 & 13.929 \\
\hline
\end{tabular}

[b] No interest-rate smoothing $\left(\alpha_{R}=0\right)$

\begin{tabular}{|c|c|c|c|c|c|c|c|c|}
\hline \multirow[b]{3}{*}{ Lump-sum taxes* } & & & & & & & & \\
\hline & $\alpha_{\pi}$ & $\alpha_{y}$ & $\alpha_{R}$ & $\psi_{1}$ & $\mathcal{W}_{0}^{\iota}$ & $\% \Phi_{c}^{\iota}$ & $\% \Delta_{E}^{\iota}$ & $\% \Delta_{V}^{\iota}$ \\
\hline & 2.0 & 0.0 & 0 & 0.5 & 65.3254 & 6.16 & -9.05 & 13.930 \\
\hline Consumption taxes & 1.5 & 0.0 & 0 & 0.2 & -54.4480 & -0.002 & -16.19 & 13.931 \\
\hline Capital-income taxes & 2.0 & 0.0 & 0 & 1.9 & -54.4648 & 0.007 & -16.18 & 13.931 \\
\hline Labor-income taxes & 1.1 & 1.0 & 0 & 0.2 & -54.4627 & 0.010 & -16.18 & 13.929 \\
\hline
\end{tabular}

\begin{tabular}{|c|c|c|c|c|c|c|c|c|}
\hline \multirow[b]{3}{*}{ Lump-sum taxes* } & \multicolumn{8}{|c|}{ [c] Taylor rules $\left(\alpha_{\pi}=1.5, \alpha_{y}=0.5, \alpha_{R}=0\right)$} \\
\hline & $\alpha_{\pi}$ & $\alpha_{y}$ & $\alpha_{R}$ & $\psi_{1}$ & $\mathcal{W}_{0}^{\iota}$ & $\% \Phi_{c}^{\iota}$ & $\% \Delta_{E}^{\iota}$ & $\% \Delta_{V}^{\iota}$ \\
\hline & 1.5 & 0.5 & 0 & 0.7 & 64.7354 & 6.44 & -9.05 & 13.929 \\
\hline Consumption taxes & 1.5 & 0.5 & 0 & 1.0 & -54.4674 & 0.008 & -16.18 & 13.929 \\
\hline Capital-income taxes & 1.5 & 0.5 & 0 & 1.0 & -54.5219 & 0.036 & -16.18 & 13.929 \\
\hline Labor-income taxes & 1.5 & 0.5 & 0 & - & - & - & - & - \\
\hline
\end{tabular}

[d] Balanced-budget targets $\left(\psi_{2}=1\right)$

\begin{tabular}{|c|c|c|c|c|c|c|c|c|}
\hline & & & & & & & & \\
\hline & $\alpha_{\pi}$ & $\alpha_{y}$ & $\alpha_{R}$ & $\psi_{1}$ & $\mathcal{W}_{0}^{\iota}$ & $\% \Phi_{c}^{\iota}$ & $\% \Delta_{E}^{\iota}$ & $\% \Delta_{V}^{\iota}$ \\
\hline cump-sum taxes & 1.1 & 0.0 & 0.9 & 0 & 65.3633 & 6.14 & -9.05 & 13.930 \\
\hline xes & 1.1 & 0.0 & 0.5 & 0 & -54.4476 & -0.002 & -16.19 & 13.930 \\
\hline Capit & - & - & - & 0 & - & - & - & - \\
\hline Labor-income taxes & 1.3 & 0.4 & 0.4 & 0 & -54.5105 & 0.029 & -16.18 & 13.929 \\
\hline
\end{tabular}

[e] Inflation targeting $\left(\hat{\pi}_{t}=0\right)$

Lump-sum taxes

\begin{tabular}{cccccccc}
\hline$\alpha_{\pi}$ & $\alpha_{y}$ & $\alpha_{R}$ & $\psi_{1}$ & $\mathcal{W}_{0}^{\iota}$ & $\% \Phi_{c}^{\iota}$ & $\% \Delta_{E}^{\iota}$ & $\% \Delta_{V}^{\iota}$ \\
\hline- & - & - & - & - & - & - & - \\
- & - & - & 0.2 & -54.4486 & -0.002 & -0.004 & 0.002 \\
- & - & - & 1.9 & -54.4526 & 0.0003 & -0.001 & 0.002 \\
- & - & - & - & - & - & - & - \\
\hline
\end{tabular}

Legend: *Any combination of passive fiscal policy for lump-sum taxes with $\psi_{1} \in[0.1,1.9]$ yields the same welfare level. 
Table 3: Optimized policy rules in a model with flexible prices

\begin{tabular}{lcccccccc}
\hline \hline & \multicolumn{8}{c}{ [a] Fully optimized monetary-policy rules } \\
\cline { 2 - 9 } & $\alpha_{\pi}$ & $\alpha_{y}$ & $\alpha_{R}$ & $\psi_{1}$ & $\mathcal{W}_{0}^{\iota}$ & $\% \Phi_{c}^{\iota}$ & $\% \Delta_{E}^{\iota}$ & $\% \Delta_{V}^{\iota}$ \\
\cline { 2 - 9 } Lump-sum taxes* & 0.9 & 0.2 & 0.0 & 3.7 & 65.3317 & 6.159 & 6.11 & 0.047 \\
Consumption taxes & 1.1 & 0.6 & 0.0 & 1.1 & -54.4477 & -0.002 & -0.003 & 0.001 \\
Capital-income taxes & 0.9 & 0.0 & 0.0 & 2.0 & -54.4474 & -0.002 & -0.003 & 0.0007 \\
Labor-income taxes & - & - & - & - & - & - & - & - \\
\hline
\end{tabular}

[b] No interest-rate smoothing $\left(\alpha_{R}=0\right)$

\begin{tabular}{|c|c|c|c|c|c|c|c|c|}
\hline & $\alpha_{\pi}$ & $\alpha_{y}$ & $\alpha_{R}$ & $\psi_{1}$ & $\mathcal{W}_{0}^{\iota}$ & $\% \Phi_{c}^{\iota}$ & $\% \Delta_{E}^{\iota}$ & $\% \Delta_{V}^{\iota}$ \\
\hline Lump-sum taxes* & 0.9 & 0.2 & 0.0 & 3.7 & 65.3317 & 6.159 & 6.11 & 0.047 \\
\hline Consumption taxes & 1.1 & 0.6 & 0.0 & 1.1 & -54.4477 & -0.002 & -0.003 & 0.001 \\
\hline Capital-income taxes & 0.9 & 0.0 & 0.0 & 2.0 & -54.4474 & -0.002 & -0.003 & 0.0007 \\
\hline Labor-income taxes & - & 0.0 & - & - & - & - & - & - \\
\hline
\end{tabular}

[c] Taylor rules $\left(\alpha_{\pi}=1.5, \alpha_{y}=0.5, \alpha_{R}=0\right)$

Lump-sum taxes

\begin{tabular}{cccccccc}
\hline$\alpha_{\pi}$ & $\alpha_{y}$ & $\alpha_{R}$ & $\psi_{1}$ & $\mathcal{W}_{0}^{\iota}$ & $\% \Phi_{c}^{\iota}$ & $\% \Delta_{E}^{\iota}$ & $\% \Delta_{V}^{\iota}$ \\
\hline 1.5 & 0.5 & 0 & - & - & - & - & - \\
1.5 & 0.5 & 0 & 1.4 & -54.4482 & -0.0019 & -0.004 & 0.002 \\
1.5 & 0.5 & 0 & 0.1 & -54.4488 & -0.0016 & -0.004 & 0.002 \\
1.5 & 0.5 & 0 & - & - & - & - & - \\
\hline
\end{tabular}

Capital-income taxes

Labor-income taxes

[d] Balanced-budget targets $\left(\psi_{2}=1\right)$

Lump-sum taxes

Consumption taxes

\begin{tabular}{cccccccc}
\hline$\alpha_{\pi}$ & $\alpha_{y}$ & $\alpha_{R}$ & $\psi_{1}$ & $\mathcal{W}_{0}^{\iota}$ & $\% \Phi_{c}^{\iota}$ & $\% \Delta_{E}^{\iota}$ & $\% \Delta_{V}^{\iota}$ \\
\hline- & - & - & 0 & - & - & - & - \\
1.3 & 0.0 & 0.0 & 0 & -54.4484 & -0.002 & -0.004 & 0.002 \\
1.0 & 0.1 & 0.0 & 0 & -54.4445 & -0.022 & -0.023 & 0.001 \\
- & - & - & 0 & - & - & - & - \\
\hline
\end{tabular}

Labor-income taxes

Legend: *The welfare function is flat over the values of $\psi_{1}$ that generate unique valid equilibria. 
Table 4: Standard deviations for the fully-optimized rules

\begin{tabular}{|c|c|c|c|c|}
\hline \multirow[b]{4}{*}{ Output } & \multicolumn{2}{|c|}{ Price rigidity } & \multicolumn{2}{|c|}{ Price flexibility } \\
\hline & \multirow[t]{2}{*}{$\alpha_{y}=0$} & \multirow{2}{*}{$\frac{\alpha_{y} \neq 0}{[\mathrm{a}] \mathrm{Lum}}$} & \multirow{2}{*}{$\frac{\alpha_{y}=0}{\mathrm{~m} \text { taxes }}$} & \multirow{2}{*}{$\alpha_{y} \neq 0$} \\
\hline & & & & \\
\hline & 0.71 & 0.63 & 0.69 & 0.69 \\
\hline Consumption & 0.51 & 0.46 & 0.50 & 0.50 \\
\hline Capital & 0.72 & 0.64 & 0.71 & 0.71 \\
\hline Inflation & 0.005 & 0.05 & 0.004 & 2.43 \\
\hline Hours worked & 0.48 & 0.35 & 0.45 & 0.45 \\
\hline Tax rate & 0.06 & 0.06 & 11.14 & 0.33 \\
\hline Bond holdings & 0.03 & 0.07 & 20.38 & 2.35 \\
\hline \multirow[t]{2}{*}{ Nominal interest rate } & 0.01 & 0.04 & 0.01 & 2.32 \\
\hline & \multicolumn{4}{|c|}{ [b] Consumption taxes } \\
\hline Output & 0.94 & 0.81 & 0.89 & 2.51 \\
\hline Consumption & 0.69 & 0.59 & 1.91 & 3.41 \\
\hline Capital & 0.73 & 0.66 & 0.45 & 2.44 \\
\hline Inflation & 0.01 & 0.04 & 0.45 & 13.34 \\
\hline Hours worked & 0.77 & 0.58 & 0.96 & 2.36 \\
\hline Tax rate & 3.47 & 2.77 & 2.03 & 3.13 \\
\hline Bond holdings & 1.58 & 1.24 & 60.88 & 11.23 \\
\hline \multirow[t]{2}{*}{ Nominal interest rate } & 0.02 & 0.03 & 0.05 & 13.17 \\
\hline & \multicolumn{4}{|c|}{ [c] Capital-income taxes } \\
\hline Output & 1.27 & 1.17 & 0.62 & 0.68 \\
\hline Consumption & 0.76 & 0.73 & 0.48 & 0.51 \\
\hline Capital & 1.82 & 1.79 & 0.64 & 0.75 \\
\hline Inflation & 0.007 & 0.06 & 2.50 & 1.58 \\
\hline Hours worked & 0.98 & 0.77 & 0.33 & 0.39 \\
\hline Tax rate & 10.01 & 8.15 & 2.63 & 3.58 \\
\hline Bond holdings & 1.46 & 2.19 & 2.32 & 1.63 \\
\hline \multirow[t]{2}{*}{ Nominal interest rate } & 0.03 & 0.04 & 2.25 & 1.58 \\
\hline & \multicolumn{4}{|c|}{ [d] Labor-income taxes } \\
\hline Output & - & 0.07 & - & - \\
\hline Consumption & - & 0.02 & - & - \\
\hline Capital & - & 0.04 & - & - \\
\hline Inflation & - & 0.15 & - & - \\
\hline Hours worked & - & 0.49 & - & - \\
\hline Tax rate & - & 0.36 & - & - \\
\hline Bond holdings & - & 0.66 & - & - \\
\hline Nominal interest rate & - & 0.09 & - & - \\
\hline
\end{tabular}

Legend: This table reports unconditional standard deviations of selected variables generated by the optimized rules of panel [a] in Table 2 and Table 3. 